\title{
Diferenças regionais de tecnologia na agricultura familiar no Brasil
}

\author{
Regional differences of technology in family farming in Brazil
}

\author{
Paulo Marcelo de Souza ${ }^{1}$ (D), Armando Fornazier ${ }^{2}$ \\ Hadma Milaneze de Souza ${ }^{3}$ (D) e Niraldo José Ponciano ${ }^{1}$
}

\begin{abstract}
Resumo: O objetivo da pesquisa foi obter uma medida da intensidade de utilização das principais tecnologias pela agricultura familiar brasileira. Para tanto, foram inicialmente obtidos 59 indicadores de uso de diversas tecnologias, para cada mesorregião geográfica. Mediante análise fatorial, esses indicadores foram sintetizados em quatro fatores, cujos valores serviram de base para o cálculo de um índice de utilização de tecnologia. Constatou-se, a partir desses índices, que há grandes diferenças regionais quanto ao uso de tecnologia na agricultura familiar. Foi constatado que os maiores índices de utilização de tecnologia concentram-se no Sul do País, mas também no Sudeste, particularmente no estado de São Paulo. Com exceção do Distrito Federal, na região Centro-Oeste predominam situações de índices médios, enquanto no Norte e Nordeste, em geral, prevalecem índices baixos ou muito baixos.
\end{abstract}

Palavras-chaves: agricultura familiar, tecnologia, análise fatorial, desigualdade.

\begin{abstract}
The objective of this research was to obtain, for the Brazilian family farming, a measure of the use of the main technologies. Initially, for each meso-region, 59 indicators of the use of various technologies were obtained. Through factor analysis, these indicators were synthesized in four factors, whose values were the basis for the estimative of an index of technology use. It was observed, from these indexes, large regional differences regarding the use of technology in family farming. It was found that the highest levels of technology use are concentrated in the South, but also in the Southeast of Brazil, especially in São Paulo state. In the Central-West, except for the Federal District, average levels prevail. However, in the North and Northeast, in most cases, low or very low levels of technology are predominant.
\end{abstract}

Keywords: family farming, technology, factor analysis, inequality.

CLASSIFICAÇÃO JEL: Q16, Q18.

Data de submissão: 16 de setembro de 2016. Data de aceite: 28 de outubro de 2018.

1. Universidade Estadual do Norte Fluminense Darcy Ribeiro (UENF), Campos dos Goytacazes

(RJ), Brasil. E-mails: pmsouza@uenf.br; ponciano@uenf.br

2. Universidade de Brasília (UNB), Brasília (DF), Brasil. E-mail: armandouenf@yahoo.com.br

3. Universidade Federal de Viçosa (UFV), Viçosa (MG), Brasil. E-mail: hadmamilaneze@hotmail.com 


\section{Introdução}

Análises diversas têm revelado grande heterogeneidade estrutural e produtiva no setor agropecuário brasileiro. Vêm sendo constatadas diferenças marcantes entre regiões e grupos de produtores quanto ao acesso aos recursos produtivos, como terra e capital, bem como a fatores internos na gestão da unidade produtiva. Essas diferenças estão também associadas a fortes disparidades, entre agricultores e regiões, em termos de desempenho econômico ou de contribuição para o valor total da produção agropecuária, caracterizando um quadro de concentração dos recursos, da produção e da renda.

Tais evidências revelam um modelo de desenvolvimento desigual e com elevados níveis de exclusão, associado às condicionantes históricas e às políticas adotadas. As políticas de modernização do setor promoveram significativas alterações na estrutura produtiva da agropecuária, induzindo ao aumento do uso de tecnologias exógenas, com impactos positivos na produtividade da terra e do trabalho. Ao mesmo tempo, geraram um quadro propício ao alargamento das disparidades entre regiões, agricultores e produtos.

Tratou-se, portanto, de um processo contraditório, questionado por inúmeros impactos negativos de ordem econômica, social e ambiental, em parte decorrentes da desigualdade com que foram distribuídos os benefícios das políticas implementadas. Nesse contexto, a modernização avançou de forma heterogênea, atingindo desigualmente regiões, atividades e agricultores.
A disparidade quanto ao emprego de tecnologia é uma das resultantes desse processo, afetando estabelecimentos de naturezas diversas. No entanto, é reconhecido que um conjunto de limitações impõe ao segmento familiar da agricultura maiores dificuldades para adequação ao padrão tecnológico vigente. A escassez de terras e recursos financeiros, a falta de assistência técnica e de acesso à política de crédito, dentre outras, são elementos que podem restringir a adoção tecnológica por agricultores familiares.

Nesse sentido, estudos têm evidenciado que a agricultura familiar apresenta baixos índices de utilização das principais tecnologias, com significativa heterogeneidade regional quanto ao uso de determinadas práticas e insumos. No entanto, há carência de estudos em nível mais desagregado, que tratem de foram geral e abrangente o uso das principais tecnologias na agricultura familiar, e que possibilitem identificar eventuais desigualdades dentro de uma mesma região ou estado. Tais análises são necessárias para maior entendimento acerca da diversidade da agricultura familiar brasileira, visando subsidiar a confecção de políticas para redução de disparidades tecnológicas entre agricultores e regiões.

Na presente pesquisa, o objetivo geral é quantificar essas diferenças, considerando-se as principais variáveis relativas ao uso de tecnologia na agricultura familiar para cada mesorregião do País. Em termos específicos, objetivou-se: identificar se há diferenças regionais quanto ao padrão tecnológico adotado pela agricultura familiar, ou seja, se há diferenças quanto ao tipo de tecnologia predominante em cada região; e verificar, mediante uma 
classificação geral da agricultura familiar quanto ao grau de utilização das principais tecnologias, as desigualdades tecnológicas regionais desse segmento.

\section{Condicionantes da adoção de tecnologia na agricultura familiar}

As disparidades tecnológicas existentes na agricultura não são recentes. Já na década de 1970 a heterogeneidade tecnológica entre estabelecimentos agropecuários era vista com preocupação (Pinto, 2000). No entanto, a partir daí, sobretudo por efeito das políticas de modernização, criou-se um contexto favorável à ampliação da lacuna existente entre estabelecimentos considerados modernos e aqueles que, por questões diversas, mantiveram-se num modelo de produção definido como tradicional.

Fortemente incentivada a partir desse momento, a adoção dos chamados "pacotes tecnológicos" contribuiu para elevar a produtividade da agricultura, mas tal processo não ocorreu de modo uniforme (Souza Filho et al., 2011). Não por acaso, estudos mais recentes revelam um quadro de concentração da produção e grandes disparidades tecnológicas na agricultura (Fornazier \& Vieira Filho, 2012; Alves \& Souza, 2015) ${ }^{1}$.

Conforme Souza Filho et al. (2011), o processo de adoção e difusão de tecnologia é de natureza complexa e intrinsecamente social. É condicionado por fatores diversos que, de acordo com a natureza das variáveis envolvidas, podem ser agrupados em: características socioeconômicas e condição do produtor; características da produção e da propriedade rural; fatores sistêmicos e características da tecnologia.

Com relação às características socioeconômicas, são importantes as variáveis relativas à condição fundiária dos agricultores, suas atitudes em relação ao risco, seu grau de organização, bem como varáveis associadas ao capital humano que possuem. Dentre as características da produção e da propriedade rural, são destacadas a localização e o tamanho da propriedade, suas condições físico-ambientais e a disponibilidade de fatores da produção. Já os direitos de propriedade da terra, as políticas públicas e o acesso à informação e aos serviços de assistência técnica e extensão rural são

1 Segundo os autores, $87 \%$ do valor da produção de 2006 foi gerada em $11,4 \%$ dos estabelecimentos. exemplos de fatores sistêmicos. Há que se observar ainda as características da tecnologia em questão, que podem ser mais ou menos exigentes em mão de obra, capital humano, tamanho e relevo da propriedade etc. (Souza Filho et al., 2011).

Esses fatores atuam sobre diferentes tipos de agricultores, condicionando sua decisão quanto ao uso de tecnologia. Porém, entende-se que algumas limitações impõem à pequena produção e aos agricultores familiares maiores dificuldades para acessar recursos, políticas, mercado etc., com reflexos negativos na adoção tecnológica, na produção e na renda.

Segundo Alves \& Souza (2015), a disparidade tecnológica na agricultura está associada às imperfeições de mercado. Essas imperfeições, ligadas ao volume produzido e transacionado pelos agricultores (e não apenas à presença de oligopólios e oligopsônios), afetam desfavoravelmente a pequena produção na negociação de preços de produtos, insumos e custo de empréstimos, inibindo a adoção de tecnologia. Outras imperfeições, como o nível de escolaridade, a moradia em regiões de acesso dispendioso às políticas públicas, as peculiaridades do cadastro bancário e a atitude diante do risco também afetam a pequena produção. A própria extensão rural, inserida nessa lógica, torna-se pouco efetiva devido a tais imperfeições, visto que elas inviabilizam a adoção de tecnologia e, consequentemente, o aumento da produtividade da terra e da mão de obra.

Em parte, a escala de produção está associada com o tamanho dos estabelecimentos, que interfere no uso de determinadas tecnologias. Conforme Souza Filho et al. (2011), essa é uma variável fundamental na agricultura, visto que determinadas tecnologias são indivisíveis e seu uso eficiente requer uma área cuja dimensão supera a da maior parte dos estabelecimentos familiares.

O tamanho geralmente reduzido dos estabelecimentos e da escala de produção da agricultura familiar tem sido apontado como argumento para sua inviabilidade econômica, quer pelas dificuldades que acarreta na adoção de tecnologias indivisíveis, quer pelas desvantagens decorrentes no acesso a serviços financeiros e aos mercados de insumos e produtos. Já Veiga (1991) argumenta que, embora exista certo patamar mínimo de tamanho para viabilização dos empreendimentos, de modo geral esse patamar é baixo, com exceção de algumas atividades que requerem maior área. 
Análise de Schneider \& Cassol (2014) revela que estabelecimentos familiares mais especializados na produção agropecuária (com receita predominantemente oriunda desta fonte) contam com maiores áreas. Em situação oposta, são menores as áreas daqueles estabelecimentos que, na tipologia dos autores, são caracterizados apenas como estabelecimentos familiares com múltiplas fontes de receita e residentes rurais, isto é, com menor ou pouca participação da produção agropecuária na receita. Helfand et al. (2014) constatam que a alta taxa de pobreza dos estabelecimentos familiares está relacionada ao tamanho reduzido de suas terras e aos baixos níveis de utilização de capital e insumos. Na concepção dos autores, tratam-se de estabelecimentos eficientes, no sentido de utilizar com eficiência o pouco de que dispõem, mas que permanecem pobres pelas limitações que enfrentam.

Portanto, há indícios de que o tamanho dos estabelecimentos é importante para definir as escolhas dos agricultores com respeito a tecnologia, produção e renda. No entanto, ressaltam Souza Filho et al. (2004), o papel exercido pelo tamanho da propriedade na adoção tecnológica depende de aspectos técnicos, econômicos e institucionais, sendo difícil analisar isoladamente a importância desse efeito.

Outra questão refere-se à falta de acesso à assistência técnica, considerada, além disso, de baixa qualidade. Desde sua gestação, o sistema público de assistência técnica e extensão rural tem sido criticado por marginalizar parcela significativa dos agricultores, em especial daqueles que não dispunham de condições desejáveis para desenvolver uma agricultura mais intensiva em capital $^{2}$ (Queda, 1987). Essa situação perdurou no período da modernização agrícola, com a criação do Sistema Empresa Brasileira de Assistência Técnica e Extensão Rural (Embrater/Emater/ Aster). Inserindo-se no arcabouço de políticas de modernização, os serviços de extensão concentraram-se nas áreas geográficas e nos produtos de resposta mais rápida aos incentivos, marginalizando a parcela dos produtores ditos de baixa renda (Martine \& Beskow, 1987).

As limitações de acesso e uso da assistência técnica existem para o conjunto da agricultura (Cassales et al., 2002), mas afetam sobretudo o segmento familiar (Guanziroli

2 Nesse sentido, argumenta-se que a extensão atingiu pequena parcela de proprietários, geralmente os mais ricos e com maior grau de escolaridade e, do ponto de vista dos assalariados, parceiros, arrendatários e pequenos proprietários, sua atuação foi pífia (Queda, 1987).
\& Cardim, 2000). Atualmente, cerca de apenas 20\% dos estabelecimentos familiares do País utilizam assistência técnica (Guanziroli et al., 2012). Trata-se de uma restrição importante, já que há indícios de correlação entre o acesso a esse serviço e a viabilidade da produção dos estabelecimentos familiares ${ }^{3}$.

O emprego de tecnologia pela agricultura familiar é também afetado pela disponibilidade de recursos financeiros e pela presença de políticas governamentais de financiamento. A escassez dos recursos financeiros é uma característica comum aos estabelecimentos familiares, e está associada às precárias condições que enfrentam para o desenvolvimento de suas atividades e à baixa produtividade do trabalho resultante.

Ademais, o crédito rural, principal política do período da modernização agrícola, foi acessado sobretudo por agricultores com mais recursos ou garantias de pagamento. Além das implicações que isso trouxe para a distribuição da riqueza (Sayad, 1984), os estímulos do crédito rural propiciaram o distanciamento tecnológico entre os agricultores que o acessaram e aqueles que, alijados dessa e de outras políticas, mantiveram-se em sistemas produtivos tradicionais (Szmrecsányi \& Ramos, 2002). Estimulados por condições de crédito e comercialização mais favoráveis, grandes propriedades aderiram a um padrão tecnológico mais elevado, deslocando frequentemente os agricultores familiares de seus mercados tradicionais (Souza Filho et al., 2004).

Essa disparidade no uso de crédito mantém-se no presente, conforme algumas análises. Dias (2010) destaca que o grupo de produtores que possui 500 ha de terra ou mais tem alto acesso aos financiamentos. Nesse grupo, os financiamentos obtidos superam em $22 \%$ os investimentos realizados. Segundo o autor, enquanto os menores estabelecimentos investem com suas próprias poupanças, os grandes contam com maior contribuição dos financiamentos com juros subsidiados. Por outro lado, Barros (2010) ressalta o baixo uso de financiamentos entre os pequenos produtores, dentre os quais apenas 18\% conseguiram acessá-los em 2006. Também Alves et al. (2012) constataram que a pequena produção gastou muito menos por hectare, possivelmente refletindo discriminação pelo mercado ou a personalidade do agricultor.

\footnotetext{
3 Por exemplo, Schneider \& Cassol (2014) observaram maior presença da assistência técnica entre os estabelecimentos familiares mais especializados na produção agropecuária (com receita predominantemente oriunda desta fonte).
} 


\section{Metodologia}

A análise do perfil e do grau de utilização de tecnologias na agricultura é um processo complexo, por envolver um número elevado de variáveis, nenhuma das quais capaz de representar ou sintetizar as informações essenciais do fenômeno. Diante dessa dificuldade, o método adotado foi a análise fatorial, tomada com base para a construção de um índice para mensurar o uso de tecnologia pela agricultura familiar. Nos itens seguintes, faz-se uma descrição desse método, do Índice de utilização de tecnologia e das variáveis utilizadas.

\subsection{Análise fatorial}

A análise fatorial consiste de um conjunto de métodos estatísticos utilizados para redução e sumarização de dados (Malhotra, 2006), e facilitar a interpretação pela descoberta de relações entre as variáveis (Manly, 2008). Mediante essa análise é possível examinar a alteração comum a variáveis latentes, com o objetivo de obter fatores comuns e explicar como estes se relacionam com os dados observados (Lattin et al., 2011). Sob certas condições, esse procedimento permite explicar o comportamento de um número relativamente grande de variáveis observadas em termos de um número relativamente pequeno de variáveis latentes ou fatores (Hoffmann, 1992).

Desse modo, o objetivo é encontrar certo número de fatores não correlacionados, de tal forma que a informação das variáveis originais esteja contida nesses fatores. Os fatores são variáveis não observáveis, com estrutura mais simples, pois são independentes e estão na direção de maior variabilidade (Mingoti, 2005).

Nesse método, as N observações das n variáveis devem ser inicialmente normalizadas. Cada variável normalizada $\mathrm{z}_{\mathrm{i}}(\mathrm{i}=1,2, \ldots, \mathrm{n})$ deve ser relacionada separadamente às variáveis hipotéticas ou fatores $\mathrm{f}_{\mathrm{i}}(\mathrm{j}=1,2, \ldots, \mathrm{m}),(\mathrm{m}<\mathrm{n}, \mathrm{N})$. Essas relações são lineares e assumem, no modelo básico de análise fatorial, a seguinte expressão analítica (Harman, 1960):

$z_{i}=a_{i 1} f_{1}+a_{i 2} f_{2}+\ldots+a_{i m} f_{m}+d_{i} u_{i}(i=1,2, \ldots, n)$

em que cada uma das n variáveis é descrita, em termos lineares, como função dos $m$ fatores comuns $\mathrm{f}_{\mathrm{i}}$ aos quais se relacionam através das cargas fatoriais ou coeficientes de conexão $\mathrm{a}_{\mathrm{ij}}$, que indicam em que medida e direção as variáveis $\mathrm{z}_{\mathrm{i}}$ estão relacionadas com o fator $\mathrm{f}_{\mathrm{i}}$; e de um fator único $\mathrm{u}_{\mathrm{i}}$ que responde pela variância remanescente.

Para saber se os fatores gerais causaram determinada relação entre as variâncias de $\mathrm{z}_{\mathrm{i}}$, é necessário que sua variância total $\left(\sigma_{i}^{2}\right)$ seja dividida em três componentes:

a) A variância comum ou comunalidade, $h_{i}^{2}$, ou seja, que proporção da variância total de $\mathrm{z}_{\mathrm{i}}$ está associada com a variância das outras variáveis ou grupo de variáveis;

b) A variância especifica ou especificidade, $\mathrm{s}_{\mathrm{i}}^{2}$, isto é, a proporção da variância total que não mostra qualquer associação com a variância das outras variáveis;

c) O erro ou distúrbio, $\mathrm{e}_{\mathrm{i}}^{2}$, que é a proporção da variância devida aos erros nas observações, ou a variáveis relevantes ao estudo, porém não consideradas no mesmo.

Os fatores únicos são sempre não relacionados com os fatores comuns e, se estes últimos não são correlacionados entre si, a variância total $\mathrm{de}_{\mathrm{i}}$, $\sigma_{\mathrm{i}}^{2}$ pode ser expressa por:

$\sigma_{\mathrm{i}}^{2}=\mathrm{a}_{\mathrm{i} 1}^{2}+\mathrm{a}_{\mathrm{i} 2}^{2}+\ldots+\mathrm{a}_{\mathrm{i} \mathrm{m}}^{2}+\mathrm{d}_{\mathrm{i}}^{2}$

em que os componentes $\mathrm{a}_{\mathrm{ij}}^{2} \mathrm{~s}$ ão denominados percentagem de conexão e correspondem à proporção da variância total da variável normalizada $z_{i}$ que é explicada pelos respectivos fatores. Em (2), o termo

$\mathrm{h}_{\mathrm{i}}^{2}=\mathrm{a}_{\mathrm{i} 1}^{2}+\mathrm{a}_{\mathrm{i} 2}^{2}+\ldots+\mathrm{a}_{\mathrm{im}}^{2}$

equivale à comunalidade da variável $\mathrm{z}_{\mathrm{i}}$, ao passo que o termo $\mathrm{d}_{\mathrm{i}}^{2}$ corresponde à unicidade, ou seja, a contribuição do fator único, indicando a extensão em que os fatores comuns falham na explicação da mudança total da variável.

Para a realização da análise fatorial é necessário inicialmente verificar se esse modelo é aplicável aos dados utilizados. Para tanto, foram empregados o teste Kaiser-Meyer-Olkin (KMO) e o teste de esfericidade de Bartlett.

O teste Kaiser-Meyer-Olkin (KMO) é uma estatística que indica a proporção da variância dos dados que pode ser considerada comum a todas as variáveis, ou seja, que pode ser atribuída a um fator comum. Quanto mais alto seu valor, situado no intervalo entre zero e um, melhor é a adequação da amostra. Por outro lado, entende-se que valores menores que 0,5 caracterizam uma amostra inadequada à análise fatorial (Malhotra, 2006).

O teste de esfericidade de Bartlett testa a hipótese de que a matriz de correlação é uma matriz identidade 
(Mingoti, 2005), ou seja, a hipótese de que não há correlação entre as variáveis. Trata-se de um teste necessário, visto que a correção entre as variáveis é condição indispensável para a realização da análise fatorial. Nesse teste, a hipótese deve ser rejeitada a um nível de significância inferior a 0,05 (Hair Junior et al., 2009; Figueiredo Filho \& Silva Júnior, 2010).

Os fatores foram obtidos pelo método dos componentes principais, cujo objetivo básico consiste em extrair fatores para maximizar a contribuição destes para a comunalidade. Para melhor interpretação dos resultados, os fatores foram submetidos a uma rotação ortogonal pelo método Varimax. Com esse procedimento, a contribuição de cada fator para a variância total é alterada sem, contudo, modificar a contribuição conjunta deles (Kim \& Mueller, 1978). Conforme Ribas \& Vieira (2011), a rotação distribui as cargas das variáveis entre os fatores de modo a eliminar as cargas intermediárias, evidenciando aquele fator em que a carga da variável é mais elevada. Ou seja, os fatores obtidos após a rotação se encontram mais estreitamente relacionados a determinados grupos de variáveis que a outros. Isso possibilita ainda "identificar" o fator, ou seja, atribuir-lhe uma denominação que resuma em alguma medida as variáveis mais estritamente relacionadas a ele, ou seja, as variáveis com carga mais elevada nesse fator.

Obtidas as cargas fatoriais, o passo seguinte consiste na determinação dos escores dos fatores. A matriz de escores fatoriais foi obtida mediante a expressão (Monteiro \& Pinheiro, 2004):

$\mathrm{EF}=\mathrm{A}^{\mathrm{t}} \cdot \mathrm{R}^{-1} \cdot \mathrm{X}^{\mathrm{t}}$

em que EF é a matriz dos escores fatoriais; $A^{T}$, a transposta da matriz das cargas fatoriais; $\mathrm{R}^{-1}$, a matriz inversa da matriz de correlação; e $X^{T}$, a transposta da matriz dos dados originais padronizados.

\section{2. Índice de utilização de tecnologia}

A partir da matriz dos escores fatoriais, foi elaborado um índice para classificar as diversas mesorregiões quanto ao grau de utilização de tecnologia de sua agricultura familiar. Esse índice pode ser obtido pela soma simples ou ponderada dos escores fatoriais (Monteiro \& Pinheiro, 2004). Na presente análise, o índice calculado resultou da soma dos escores fatoriais, ponderada pela proporção de explicação da variância total representada por cada fator, tal como em Melo \& Parré (2007). Esse índice, aqui
Quadro 1. Intervalos para classificação das mesorregiões, definidos com base na média $(\mathrm{M})$ e no desvio padrão $(\delta)$ dos escores fatoriais e do Índice de utilização de tecnologia

\begin{tabular}{|l|l|}
\hline Grau de utilização de tecnologia & \multicolumn{1}{c|}{ Intervalos } \\
\hline Extremamente baixo & $\mathrm{IT} \leq \mathrm{M}-1,5 \delta$ \\
\hline Muito baixo & $\mathrm{M}-1,5 \delta<\mathrm{IT} \leq \mathrm{M}-1,0 \delta$ \\
\hline Baixo & $\mathrm{M}-1,0 \delta<\mathrm{IT} \leq \mathrm{M}-0,5 \delta$ \\
\hline Médio baixo & $\mathrm{M}-0,5 \delta<\mathrm{IT} \leq \mathrm{M}$ \\
\hline Médio alto & $\mathrm{M}<\mathrm{IT} \leq \mathrm{M}+0,5 \delta$ \\
\hline Alto & $\mathrm{M}+0,5 \delta<\mathrm{IT} \leq \mathrm{M}+1,0 \delta$ \\
\hline Muito alto & $\mathrm{M}+1,0 \delta<\mathrm{IT} \leq \mathrm{M}+1,5 \delta$ \\
\hline Extremamente alto & $\mathrm{IT}>\mathrm{M}+1,5 \delta$ \\
\hline
\end{tabular}

Fonte: Elaboração própria.

referido como Índice de utilização de tecnologia (IT) ${ }^{4}$, foi obtido pela expressão:

$\mathrm{IT}=\frac{\sum_{\mathrm{i}=1}^{\mathrm{n}} \mathrm{w}_{\mathrm{i}} \mathrm{F}_{\mathrm{i}}}{\sum_{\mathrm{i}=1}^{\mathrm{n}} \mathrm{w}_{\mathrm{i}}}$

em que $\mathrm{w}_{\mathrm{i}}$ é a proporção da variância explicada pelo fator ie $\mathrm{F}_{\mathrm{i}}$ o respectivo valor desse fator.

Com um procedimento semelhante ${ }^{5}$ ao adotado por Stege \& Parré (2011), os escores fatoriais (para cada fator e mesorregião) serviram de base para classificar as mesorregiões em seis graus de intensidade de utilização das tecnologias associadas a cada fator. Do mesmo modo, uma classificação geral das mesorregiões foi obtida a partir dos índices de utilização de tecnologia. Os limites para essa classificação foram estabelecidos com base na média e no desvio dos escores fatoriais e dos índices de utilização de tecnologia, conforme Quadro 1.

\subsection{Variáveis e fonte dos dados}

Diante do caráter multidimensional da modernização da agricultura, torna-se necessário grande número de indicadores para descrevê-la. No presente estudo, a

4 Optou-se por essa denominação, em vez de "índice de desenvolvimento", para evitar associações com o termo desenvolvimento rural, que é mais amplo e não se resume à questão tecnológica. No debate sobre o desenvolvimento rural, discute-se inclusive o padrão tecnológico vigente, por seus impactos econômicos, sociais e ambientais.

5 No trabalho citado os intervalos foram construídos com amplitude de um desvio padrão. Aqui, optou-se por uma amplitude de meio desvio padrão, necessária para obter maior número de classes de utilização de tecnologia. 
seleção das variáveis para tal caracterização partiu do pressuposto de que a modernização agrícola implica aumento no uso de tecnologias ditas modernas (máquinas, uso de adubos químicos, fertilizantes, irrigação, controle de pragas, assistência técnica etc.), que resultam em crescente produtividade da terra e do trabalho.

Como o interesse da análise reside na intensidade do uso das tecnologias, a maioria das variáveis é expressa em relação à mão de obra ocupada, em equivalentes-homem-ano (EH), e em relação à área explorada, em hectares (AE). A área explorada é obtida pela soma das áreas ocupadas com lavouras permanentes e temporárias, com pastagens e matas plantadas, e as áreas cobertas por pastagens e matas naturais (Hoffmann, 1992). Para o cálculo do número de equivalentes-homem, foram utilizados os fatores (Kageyama \& Silva, 1983):homens maiores de 14 anos = 1,0 EH; mulheres maiores de 14 anos $=0,5 \mathrm{EH}$ (familiares), 1,0 EH (empregados) ou $0,66 \mathrm{EH}$ (parceiros / outra condição); menores de 14 anos: $0,4 \mathrm{EH}$ (familiares) ou 0,5 EH (empregados e parceiros).

Para caracterizar o uso de tecnologia pela agricultura familiar nas mesorregiões foram inicialmente calculadas as variáveis apresentadas no Quadro 2.

Quadro 2.Relação das variáveis empregadas na análise fatorial

\begin{tabular}{|c|c|}
\hline $\begin{array}{l}\text { X01: Proporção dos estabelecimentos com acesso à assistência } \\
\text { técnica }\end{array}$ & X31: Semeadeiras e/ou plantadeiras/AE \\
\hline X02: Proporção dos estabelecimentos com uso de energia elétrica & X32: Colheitadeiras/AE \\
\hline X03: Proporção dos estabelecimentos com uso de tração animal & X33: Pulverizadores e/ou atomizadores/AE \\
\hline X04: Proporção dos estabelecimentos com uso de tração mecânica & X34: Adubadeiras e/ou distribuidoras de calcário/AE \\
\hline X05: Proporção dos estabelecimentos com uso de irrigação & X35: Ceifadeiras (picadeira de forragens) / AE \\
\hline X06: Área dos estabelecimentos com uso de irrigação/AE & X36: Valor dos financiamentos obtidos (Mil Reais)/EH \\
\hline X07: Proporção dos estabelecimentos com uso de adubação & X37: Valor dos investimentos (Mil Reais)/EH \\
\hline X08: Proporção dos estabelecimentos com uso de agrotóxicos & X38: Valor dos veículos, tratores, máquinas e implementos / EH \\
\hline $\begin{array}{l}\text { X09: Proporção dos estabelecimentos com uso de calcário/ } \\
\text { corretivos }\end{array}$ & X39: Valor dos prédios, instalações e outras benfeitorias/EH \\
\hline X10: Proporção dos estabelecimentos com agricultura orgânica & X40: Valores dos animais (reprodução, criação e outros fins)/EH \\
\hline X11: Proporção dos estabelecimentos com acesso a financiamento & X41: Despesas com Adubos/EH \\
\hline X12: Valor dos financiamentos obtidos/AE & X42: Despesas com corretivos do solo/EH \\
\hline X13: Valor dos investimentos / AE & X43: Despesas com sementes e mudas/EH \\
\hline X14: Valor dos veículos, tratores, máquinas e implementos / AE & X44: Despesas com agrotóxicos/EH \\
\hline X15: Valor dos prédios, instalações e outras benfeitorias/AE & X45: Despesas com medicamentos para animais/EH \\
\hline X16: Valores dos animais (reprodução, criação e outros fins) / AE & X46: Despesas com sal e rações/EH \\
\hline X17: Despesas com Adubos/AE & X47: Despesa com Energia elétrica/EH \\
\hline X18: Despesas com corretivos do solo/AE & X48: Despesas com combustíveis/EH \\
\hline X19: Despesas com sementes e mudas / AE & X49: Valor das receitas obtidas no estabel. no ano/EH \\
\hline X20: Despesas com agrotóxicos / AE & X50: Valor da produção dos estabel. no ano/EH \\
\hline X21: Despesas com medicamentos para animais/AE & X51: Tratores/EH \\
\hline X22: Despesas com sal e rações / AE & X52: Arados /EH \\
\hline X23: Despesa com Energia elétrica/AE & X53: Grades e/ou enxadas rotativas/EH \\
\hline X24: Despesas com combustíveis/AE & X54: Roçadeiras/EH \\
\hline X25: Valor das receitas obtidas no estabel. no ano/AE & X55: Semeadeiras e/ou plantadeiras/EH \\
\hline X26: Valor da produção dos estabel. no ano/AE & X56: Colheitadeiras/EH \\
\hline X27: Tratores/AE & X57: Pulverizadores e/ou atomizadores/EH \\
\hline X28: Arados/AE & X58: Adubadeiras e/ou distribuidoras de calcário/EH \\
\hline X29: Grades e/ou enxadas rotativas/AE & X59: Ceifadeiras (picadeira de forragens)/EH \\
\hline X30: Roçadeiras / AE & \\
\hline
\end{tabular}

Fonte: Elaborado pelos autores. 
A elaboração dessas variáveis baseou-se em outros estudos abordando o processo de modernização da agricultura (Hoffmann \& Kassouf, 1989; Hoffmann, 1992; Tarsitano, 1992; Espírito-Santo, 1998; Souza \& Lima, 2003; Rebello et al., 2011; Madeira, 2012). Nesse processo, buscou-se ainda explorar os dados desagregados (por exemplo, criando variáveis para os itens de despesa, para os diversos implementos etc.).

Essas informações provieram das tabulações especiais do Censo Agropecuário 2006, obtidas segundo critérios estabelecidos pela Lei n. 11.326 (Lei da Agricultura Familiar), e foram obtidas no Sistema de Recuperação Automática (Sidra), do Instituto Brasileiro de Geografia e Estatística (Instituto Brasileiro de Geografia e Estatísitca, 2016). As análises foram realizadas com o uso do software livre PSPP, uma alternativa para o programa SPSS (StatisticalPackage for the Social Sciences), e das planilhas eletrônicas do Microsoft Excel.

\section{Resultados e discussão}

\subsection{Extração e "identificação" dos fatores de modernização}

No intuito de verificar se os dados são apropriados para a análise fatorial, foi realizado o teste de esfericidade de Bartlett (TEB), cujo objetivo é constatar a presença de correlações entre as variáveis. $\mathrm{O}$ valor obtido para esse teste $(18.782,07)$ é significativo a $1 \%$ de probabilidade, resultado que permite rejeitar a hipótese nula de que a matriz de correlação seja uma matriz identidade, isto é, de que as variáveis não são correlacionadas. Realizou-se ainda o teste de Kaiser-Meyer-Olkin (KMO), cujo valor obtido $(1,00)$ indica que os dados são adequados à realização da análise fatorial.

Conforme Tabela 1, foram obtidos oito fatores com raiz característica maior que a unidade. A contribuição acumulada desses fatores para a variância total é de $87,06 \%$. Uma vez que não existe critério único para definir o número de fatores principais que devem ser extraídos, optou-se pela caracterização do processo de utilização de tecnologia na agricultura familiar através dos quatro primeiros fatores, que, conjuntamente, explicam 77,17\% da variância total das variáveis analisadas.

Feita a rotação, a contribuição dos fatores F1, F2, F3 e F4 para explicação da variância total dos indicadores utilizados passa a ser de $31,42 \%, 24,20 \%$, $13,13 \%$ e 8,41, respectivamente, com contribuição conjunta de 77,17\% . Na Tabela 2 encontram-se as cargas fatoriais, as comunalidades e o percentual da variância total dos indicadores. Para melhor interpretação, as cargas fatoriais com valor superior a 0,600 estão em negrito, buscando evidenciar as variáveis mais fortemente associadas a determinado fator.

Com base nos valores das cargas fatoriais, observa-se que o primeiro fator apresenta correlação positiva mais estreita com a proporção dos estabelecimentos que recebem assistência técnica (X1), que usam tração mecânica (X4), agrotóxicos (X8) e fazem aplicação de calcário e/ ou outros corretivos (X9). Está associado também com o valor dos financiamentos obtidos (X12 e X36) e com as despesas com insumos diversos, como adubos (X41), corretivos do solo (X42), agrotóxicos (X44 e X20) e combustíveis (X48). Além das despesas, o fator também está correlacionado com o valor investido em veículos, tratores, máquinas

Tabela 1. Fatores obtidos pelo método dos componentes principais

\begin{tabular}{cccc}
\hline Fator & Raiz característica & $\begin{array}{c}\text { Variância explicada pelo fator } \\
(\boldsymbol{\%})\end{array}$ & $\begin{array}{c}\text { Variância acumulada } \\
(\%)\end{array}$ \\
\hline 1 & 30,64 & 51,93 & 51,93 \\
2 & 7,78 & 13,18 & 65,11 \\
3 & 4,16 & 7,05 & 72,16 \\
4 & 2,95 & 5,01 & 77,17 \\
5 & 1,83 & 3,10 & 80,27 \\
6 & 1,58 & 2,68 & 82,95 \\
8 & 1,28 & 2,17 & 85,11 \\
\hline
\end{tabular}

Fonte: Dados da pesquisa. 
Tabela 2. Cargas fatoriais após a rotação ortogonal e comunalidades obtidas na análise fatorial dos indicadores de utilização de tecnologia pela agricultura familiar das mesorregiões brasileiras, 2006

\begin{tabular}{|c|c|c|c|c|c|}
\hline \multirow{2}{*}{ Variável } & \multicolumn{4}{|c|}{ Carga Fatorial } & \multirow{2}{*}{ Comunalidades } \\
\hline & F1 & F2 & F3 & F4 & \\
\hline $\mathrm{X} 1$ & 0,663 & 0,209 & 0,463 & 0,300 & 0,788 \\
\hline $\mathrm{X} 2$ & 0,143 & 0,405 & 0,436 & 0,484 & 0,609 \\
\hline $\mathrm{X} 3$ & $-0,055$ & $-0,327$ & 0,230 & 0,634 & 0,565 \\
\hline $\mathrm{X} 4$ & 0,639 & 0,351 & 0,245 & 0,369 & 0,728 \\
\hline X5 & $-0,084$ & 0,822 & 0,125 & $-0,035$ & 0,700 \\
\hline X6 & $-0,049$ & 0,888 & 0,055 & 0,000 & 0,794 \\
\hline $\mathrm{X} 7$ & 0,508 & 0,458 & 0,315 & 0,400 & 0,727 \\
\hline $\mathrm{X} 8$ & 0,611 & 0,337 & 0,010 & 0,533 & 0,771 \\
\hline X9 & 0,637 & 0,497 & 0,379 & 0,182 & 0,830 \\
\hline $\mathrm{X} 10$ & $-0,116$ & 0,250 & 0,049 & 0,200 & 0,118 \\
\hline X11 & 0,445 & $-0,118$ & 0,018 & 0,761 & 0,791 \\
\hline $\mathrm{X} 12$ & 0,677 & 0,335 & 0,131 & 0,515 & 0,853 \\
\hline $\mathrm{X} 13$ & 0,320 & 0,845 & 0,251 & 0,191 & 0,916 \\
\hline X14 & 0,598 & 0,729 & 0,141 & 0,171 & 0,938 \\
\hline X15 & 0,236 & 0,896 & 0,202 & 0,136 & 0,918 \\
\hline $\mathrm{X} 16$ & 0,174 & 0,318 & 0,685 & 0,289 & 0,684 \\
\hline X17 & 0,500 & 0,794 & 0,074 & 0,115 & 0,899 \\
\hline $\mathrm{X} 18$ & 0,310 & 0,835 & 0,168 & $-0,073$ & 0,827 \\
\hline X19 & 0,170 & 0,845 & 0,106 & 0,041 & 0,756 \\
\hline $\mathrm{X} 20$ & 0,653 & 0,469 & 0,053 & 0,042 & 0,651 \\
\hline X21 & 0,343 & 0,449 & 0,704 & 0,165 & 0,842 \\
\hline $\mathrm{X} 22$ & 0,297 & 0,328 & 0,475 & 0,489 & 0,661 \\
\hline $\mathrm{X} 23$ & 0,111 & 0,914 & 0,210 & 0,054 & 0,895 \\
\hline X24 & 0,400 & 0,864 & 0,094 & 0,072 & 0,921 \\
\hline $\mathrm{X} 25$ & 0,219 & 0,885 & $-0,036$ & $-0,044$ & 0,834 \\
\hline $\mathrm{X} 26$ & 0,241 & 0,877 & $-0,017$ & 0,004 & 0,828 \\
\hline $\mathrm{X} 27$ & 0,490 & 0,802 & 0,072 & 0,002 & 0,888 \\
\hline X28 & 0,465 & 0,402 & $-0,004$ & 0,620 & 0,762 \\
\hline X29 & 0,465 & 0,710 & $-0,074$ & 0,321 & 0,829 \\
\hline X30 & 0,339 & 0,634 & $-0,173$ & 0,061 & 0,551 \\
\hline X31 & 0,724 & 0,099 & 0,053 & 0,531 & 0,819 \\
\hline X32 & 0,778 & 0,109 & 0,116 & 0,402 & 0,792 \\
\hline X33 & 0,813 & 0,441 & 0,099 & 0,172 & 0,895 \\
\hline X34 & 0,825 & 0,358 & 0,149 & 0,095 & 0,840 \\
\hline X35 & 0,066 & 0,415 & 0,521 & 0,330 & 0,557 \\
\hline X36 & 0,791 & $-0,042$ & 0,374 & 0,309 & 0,863 \\
\hline X37 & 0,572 & 0,134 & 0,710 & 0,066 & 0,854 \\
\hline X38 & 0,860 & 0,209 & 0,375 & 0,141 & 0,944 \\
\hline X39 & 0,588 & 0,363 & 0,617 & 0,115 & 0,871 \\
\hline X40 & 0,124 & $-0,338$ & 0,761 & $-0,199$ & 0,748 \\
\hline X41 & 0,800 & 0,283 & 0,245 & 0,116 & 0,794 \\
\hline
\end{tabular}

Fonte: Dados da pesquisa. 
Tabela 2. Continuação...

\begin{tabular}{|c|c|c|c|c|c|}
\hline \multirow{2}{*}{ Variável } & \multicolumn{4}{|c|}{ Carga Fatorial } & \multirow{2}{*}{ Comunalidades } \\
\hline & F1 & F2 & F3 & F4 & \\
\hline $\mathrm{X} 42$ & 0,642 & 0,268 & 0,437 & $-0,214$ & 0,721 \\
\hline $\mathrm{X} 43$ & 0,574 & 0,493 & 0,311 & 0,134 & 0,687 \\
\hline X44 & 0,768 & 0,151 & 0,126 & 0,006 & 0,629 \\
\hline X45 & 0,266 & $-0,176$ & 0,875 & $-0,121$ & 0,882 \\
\hline $\mathrm{X} 46$ & 0,289 & $-0,040$ & 0,719 & 0,270 & 0,675 \\
\hline X47 & 0,426 & 0,392 & 0,719 & 0,009 & 0,852 \\
\hline X48 & 0,794 & 0,197 & 0,493 & $-0,053$ & 0,915 \\
\hline X49 & 0,622 & 0,424 & 0,299 & $-0,095$ & 0,665 \\
\hline X50 & 0,628 & 0,331 & 0,386 & $-0,073$ & 0,658 \\
\hline X51 & 0,841 & 0,348 & 0,274 & 0,015 & 0,904 \\
\hline X52 & 0,590 & 0,101 & 0,144 & 0,619 & 0,762 \\
\hline $\mathrm{X} 53$ & 0,785 & 0,235 & 0,157 & 0,343 & 0,814 \\
\hline X54 & 0,675 & 0,250 & 0,060 & $-0,025$ & 0,522 \\
\hline X55 & 0,801 & $-0,045$ & 0,178 & 0,425 & 0,856 \\
\hline X56 & 0,806 & $-0,033$ & 0,230 & 0,300 & 0,794 \\
\hline X57 & 0,917 & 0,149 & 0,171 & 0,136 & 0,911 \\
\hline X58 & 0,886 & 0,109 & 0,235 & 0,026 & 0,853 \\
\hline X59 & 0,107 & 0,084 & 0,698 & 0,217 & 0,553 \\
\hline \% da variância & $31,42 \%$ & $24,20 \%$ & $13,13 \%$ & $8,41 \%$ & \\
\hline
\end{tabular}

Fonte: Dados da pesquisa.

e implementos (X38), e com as variáveis que captam a quantidade de cada um desses itens, mais especificamente tratores(X51), grades/enxadas rotativas (X53), roçadeiras (X54), semeadeiras / plantadeiras (X31 e X55), colheitadeiras(X32eX56),pulverizadores/atomizadores(X33eX57) e adubadeiras/distribuidoras de calcário (X34 e X58). Finalmente, esse fator se correlaciona com o valor das receitas (X49) e da produção dos estabelecimentos (X50) por equivalente-homem ocupado, indicadores que captam a produtividade da mão de obra.

Observa-se que a maior parte das variáveis relacionadas ao fator 1 têm como denominador o número de equivalentes-homem empregados no processo produtivo. As exceções são os valores dos financiamentos obtidos e das despesas com agrotóxicos, bem como do número de alguns implementos (semeadeiras, colheitadeiras, pulverizadores e adubadeiras). Esses indicadores se relacionam com o fator 1 tanto quando expressos em termos de área explorada quanto em termos de equivalentes-homem. Porém, por simplificação, a denominação intensidade da relação capital/trabalho foi conferida a esse fator, visto que sua dinâmica reflete a intensificação do uso de financiamento e de tecnologias diversas, com impactos positivos na produtividade do fator trabalho.

Já o fator 2 é positivamente correlacionado com um conjunto de variáveis que captam tecnologias diversas, expressas em relação à área explorada. Neste caso, as cargas fatoriais mais elevadas ocorrem para as variáveis: proporção dos estabelecimentos que usam irrigação (X5) e área em que essa prática é adotada (X6); valor dos investimentos (X13), mais especificamente do valor imobilizado em veículos, tratores, máquinas e implementos (X14), e em prédios, instalações e outras benfeitorias (X15); número de tratores (X27); grades e/ou enxadas rotativas (X29) e roçadeiras (X30); despesas com adubos(X17), corretivos do solo (X18),sementes e mudas (X19), energia elétrica (X23) e combustíveis (X24). Esse fator se relaciona ainda com indicadores que captam a produtividade da terra, como é o caso do valor das receitas obtidas nos estabelecimentos no ano (X25) e o valor da produção dos estabelecimentos no ano (X26), ambos expressos em termos de unidade de 
área explorada. Portanto, por simplificação, esse fator foi denominado intensidade da exploração da terra.

$\mathrm{O}$ fator 3 está particularmente relacionado às despesas e investimentos na produção animal. Esse fator tem correlação positiva com o valor dos animais de reprodução, criação e outros fins, por área explorada (X16) e por equivalente-homem (X40), e com as despesas com medicamentos para animais, também expressas em termos de área explorada (X21) e de equivalente-homem (X45). Também se correlaciona mais estreitamente com o valor dos investimentos (X37), dos prédios, instalações e outras benfeitorias (X39), com as despesas com sal e rações (X46), com energia elétrica (X47), e com o número de ceifadeiras / picadeiras de forragens (X59), todas elas expressas em termos de equivalente-homem. Para resumir, atribui-se a esse fator a denominação intensividade da produção animal.

Já o fator 4 correlaciona-se mais fortemente com as variáveis: proporção dos estabelecimentos com tração animal (X3); proporção dos estabelecimentos que obtiveram financiamento (X11); e ao número de arados, seja por área explorada (X28) ou equivalente-homem (X52). A associação entre esses implementos e a tração animal deve-se, provavelmente, ao predomínio numérico, em determinadas mesorregiões, dos arados movidos por animais ${ }^{6}$. Já a correlação com a proporção de estabelecimentos que obtiveram financiamentos deve estar associada a contratos de crédito de baixo

6 A fonte não permite distinguir se esses implementos são acionados por tração mecânica ou animal. No entanto, observa-se que o número de arados na agricultura familiar no País é quase o dobro do número de tratores. Na região Nordeste, há mais de sete arados por trator. Diante desses números, pode-se inferir que a correlação encontrada é devida ao predomínio, sobretudo na região Nordeste, dos arados de tração animal. valor, já que as variáveis relativas ao valor total dos financiamentos correlacionaram-se mais fortemente com os dois primeiros fatores. Por simplificação, o quarto fator foi denominado intensidade de uso da tração animal.

\subsection{A situação das regiões quanto aos escores dos fatores de modernização}

Obtidos e "identificados" os fatores, o passo seguinte foi calcular os escores fatoriais de cada um deles, para cada mesorregião. Os índices correspondentes a esses escores, obtidos por interpolação para uma escala de 0 a 100, estão no Apêndice A. A partir desses índices, as mesorregiões foram classificadas segundo o grau de utilização das tecnologias associadas a cada fator, com base nos limites estabelecidos no Quadro 1.

Uma síntese das classificações obtidas pelas mesorregiões para a intensidade da relação capital/trabalho, dentro de cada região, é representada na Figura 1. Pode-se observar que a relação capital trabalho mais elevada, com índices considerados extremamente altos, encontra-se principalmente nos estados da região Sul, mas também no Sudeste. Essa classificação foi obtida em mesorregiões: de São Paulo (mesorregiões de Piracicaba, Ribeirão Preto, Assis e São José do Rio Preto), do Paraná (oeste paranaense, centro ocidental paranaense, sudeste paranaense e norte central paranaense), do Rio Grande do Sul (noroeste rio-grandense e nordeste rio-grandense) e de Santa Catarina (norte catarinense).

Nesses estados, concentram-se também regiões com índices muito altos para a relação capital/trabalho. É o que se observa nas regiões de Araçatuba, Campinas, Bauru e Marília, no estado de São Paulo; nas regiões serrana e Vale do Itajaí, em Santa Catarina; e nas regiões centro ocidental rio-grandense e norte pioneiro paranaense.

Figura 1. Distribuição das mesorregiões (\%) conforme classificação obtida para o fator 1 (intensidade da relação capital/trabalho)
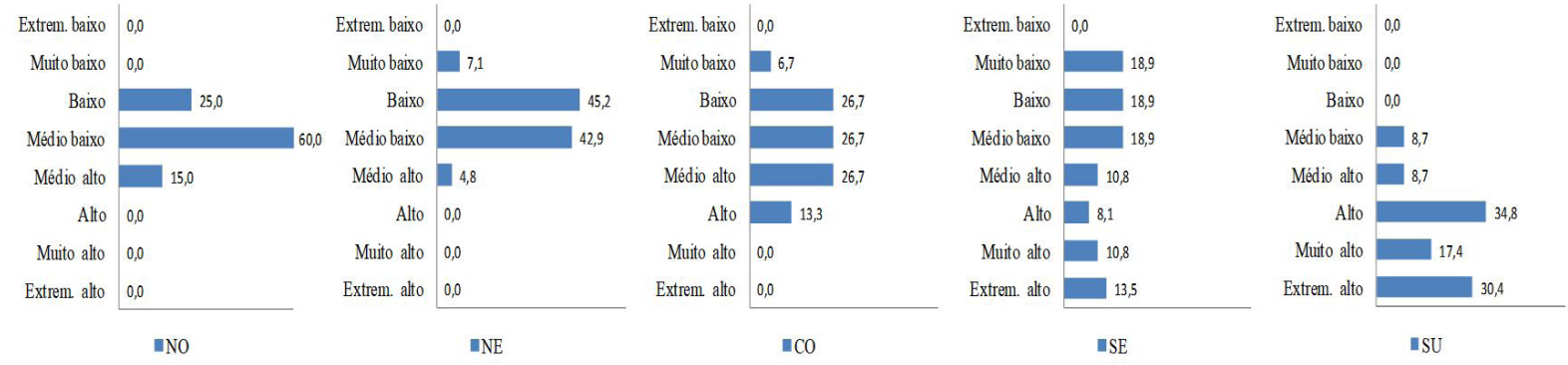

Fonte: Resultados da pesquisa. 
Em seguida aparecem, com alta intensidade da relação capital/trabalho, novamente regiões de Santa Catarina (oeste catarinense, grande Florianópolis e sul catarinense), do Paraná (centro-sul paranaense, centro oriental paranaense, sudoeste paranaense e metropolitana de Curitiba), de São Paulo (macro metropolitana paulista e litoral sul paulista) e do Rio Grande do Sul (centro oriental rio-grandense). Além desses estados, também em Mato Grosso, nas regiões norte mato-grossense e nordeste mato-grossense, e em Minas Gerais, na região sul/sudoeste de Minas, essa classificação ocorre.

Relação capital/trabalho um pouco superior à média (médio/alto) é encontrada em regiões de São Paulo (Itapetininga, Presidente Prudente e metropolitana), do Rio Grande do Sul (Metropolitana de Porto Alegre e Sudoeste Rio-grandense), Minas Gerais (Triângulo Mineiro/ Alto Paranaíba) e Mato Grosso (sudeste mato-grossense). Essa classificação ocorre também para regiões específicas do Acre (Vale do Acre), do Amapá (norte do Amapá), de Tocantins (oriental do Tocantins), de Mato Grosso do Sul (sudoeste e leste), de Goiás (sul goiano), do Maranhão (sul maranhense) e do Ceará (centro-sul cearense).

Valores ligeiramente abaixo da média, aqui denominados médio / baixos, são encontrados em grande número de mesorregiões, dispersas em todo o território nacional. No entanto, essa é a condição da maior parte das mesorregiões da região Norte, de expressiva parcela dos casos da região Nordeste, Centro-Oeste e Sudeste. Na região Sul, essa classificação ocorre apenas nas regiões noroeste paranaense e sudoeste rio-grandense, já que em todas as demais a relação capital/trabalho ficou acima da média.

Excetuando-se a região Sul, nas demais é encontrada proporção significativa de mesorregiões com valores baixos para a relação capital/trabalho. Essa proporção é mais elevada na região Nordeste, atingindo quase metade das mesorregiões, mas é também expressiva nas regiões Centro-Oeste, Norte e Sudeste. Nesta última há também contingente expressivo de mesorregiões com relação capital/trabalho muito baixa, situadas em Minas Gerais (norte de minas, central mineira, metropolitana de Belo Horizonte e Zona da Mata) e Rio de Janeiro (baixadas, sul fluminense, metropolitana do Rio de Janeiro). Essa condição ocorre ainda no Nordeste, apenas nas regiões metropolitana de Fortaleza (CE), mata paraibana (PB) e mata pernambucana (PE), e no Centro-Oeste, no Distrito Federal.

Quando considerada a intensidade de exploração da terra, o enquadramento das mesorregiões é o descrito pela Figura 2. Também neste caso, valores mais elevados ocorrem com mais frequência no Sul e no Sudeste, mas são também encontrados nas regiões Nordeste e Centro-Oeste. A intensidade de exploração da terra mostrou-se: extremamente alta, em regiões de São Paulo (metropolitana de São Paulo e macro metropolitana paulista), Rio de Janeiro (metropolitana do Rio de Janeiro) e Distrito Federal; muito alta, em São Paulo (Campinas) e Ceará (metropolitana de Fortaleza); e alta, no Espírito Santo (litoral norte, noroeste e central), em São Paulo (Piracicaba e litoral sul paulista), no Rio de Janeiro (baixadas e centro fluminense), em Sana Catarina (sul catarinense, grande Florianópolis e Vale do Itajaí), no Paraná (metropolitana de Curitiba), no Rio Grande do Sul (metropolitana de Porto Alegre), em Pernambuco (mata pernambucana e metropolitana de Recife) e na Paraíba (mata paraibana).

Valores ligeiramente superiores à media (médio alto) são encontrados principalmente no Sudeste, no Nordeste e no Sul, onde essa classificação atinge parcela significativa das mesorregiões. Nessas regiões, são poucas as situações

Figura 2. Distribuição das mesorregiões (\%) conforme classificação obtida para o fator 2 (intensidade de exploração da terra)
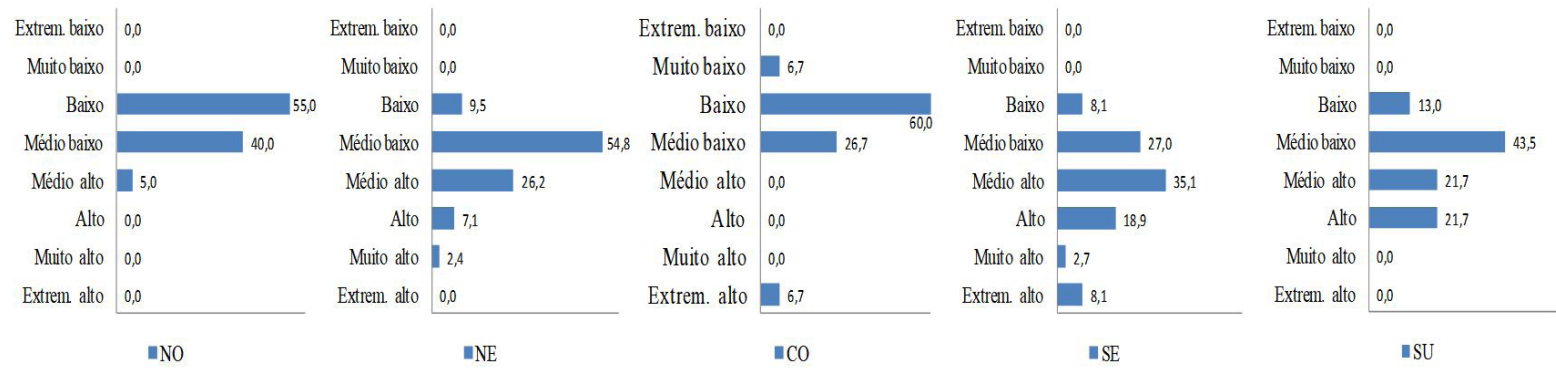

Fonte: Resultados da pesquisa. 
de agricultura familiar com baixos níveis de intensidade da exploração da terra. Por outro lado, nas regiões Norte (exceto pela mesorregião metropolitana de Belém) e na região Centro-Oeste (exceção do Distrito Federal), a maior parte das mesorregiões apresenta índices médio baixos, baixos ou muito baixos de exploração da terra.

Na Figura 3 pode-se observar a distribuição das mesorregiões em termos de intensividade da produção animal. Nota-se que explorações animais mais intensivas tendem a se concentrar em mesorregiões do Centro-Oeste e do Sudeste, embora também ocorram em localidades específicas das regiões Norte e Sul. Valores considerados extremamente altos para esse fator foram obtidos em: Minas Gerais (central mineira, Triângulo Mineiro/ Alto Paranaíba, oeste de Minas, Campo das Vertentes e metropolitana de Belo Horizonte), Rio de Janeiro (sul fluminense, baixadas, noroeste fluminense), São Paulo (Vale do Paraíba Paulista), Goiás (sul goiano), Mato Grosso (sudoeste), Mato Grosso do Sul (centro norte) e Santa Catarina (oeste catarinense).

Valores muito altos estão associados a mesorregiões de Goiás (centro e noroeste), Mato Grosso (sudeste e nordeste), Mato Grosso do Sul (leste), Distrito Federal, São Paulo (Araçatuba, Bauru e Marília), Minas Gerais (noroeste), Rio de Janeiro (centro fluminense), Santa Catarina (sul) e Rio Grande do Sul (sudoeste). Explorações animais com altos índices de intensividade ocorrem em regiões de São Paulo (Presidente Prudente, Piracicaba, São José do Rio Preto e Campinas), Minas Gerais (Zona da Mata e Vale do Rio Doce), Rio de Janeiro (metropolitana), Mato Grosso (norte), Mato Grosso do Sul (sudoeste e Pantanais), Pará (sudeste), Rondônia (leste) e Paraná (sudoeste).

Escores classificados como médios altos são a realidade de parcela significativa das mesorregiões do Sudeste, do Sul e do Centro-Oeste. Essa situação ocorre também na região Norte, porém apenas nas mesorregiões de Madeira-Guaporé (RO) e ocidental do Tocantins (TO). Sem exceções, todas as mesorregiões do Nordeste apresentam grau de intensividade da produção animal abaixo da média. Nessa região predominam indicadores classificados como baixos ou muito baixos. Essa é também a situação predominante na agricultura familiar da região Norte, com exceção de algumas regiões do Pará, de Rondônia e de Tocantins, já mencionadas.

Um resumo da distribuição regional das classificações para o fator intensidade de uso da tração animal encontra-se na Figura 4. Neste caso, valores mais elevados são encontrados principalmente na região Sul. Com exceção de uma única região, a norte central paranaense, em todas as demais esse fator apresenta escores acima da média, com parcela expressiva de regiões com escores muito altos ou extremamente altos. Em determinadas mesorregiões do Sudeste, valores altos, ou pelo menos acima da média, são também encontrados. Já nas regiões Norte e Centro-Oeste, em quase todos os casos, esse indicador fica abaixo da média.

A principal diferença, neste caso, é que indicadores acima da média são encontrados em parcela expressiva das regiões do Nordeste, em alguns casos atingindo a classificação extremamente alto, como ocorre no sertão alagoano(AL), e muito alto, situação observada nas mesorregiões agreste e central potiguar $(\mathrm{RN})$, Borborema (PB) e Jaguaribe (CE).

É necessário ressaltar as diferentes motivações para a importância do uso da tração animal nessas duas regiões. Cerca de 20 e $37 \%$ dos estabelecimentos de agricultura familiar nas regiões Nordeste e Sul, respectivamente, se utilizam de força animal. No entanto, apenas cerca de $18 \%$ dos estabelecimentos do Nordeste empregam a tração mecânica (isoladamente ou em conjunto com a animal), contra aproximadamente $48 \%$ dos estabelecimentos da região Sul (Guanziroli \& Cardim, 2000). Desse quadro é

Figura 3. Distribuição das mesorregiões (\%) conforme classificação obtida para o fator 3 (intensividade da

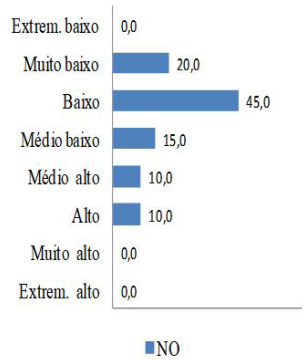

Fonte: Resultados da pesquisa.

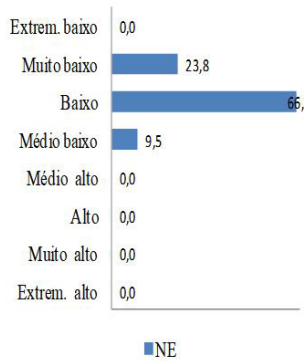

NE produção animal)

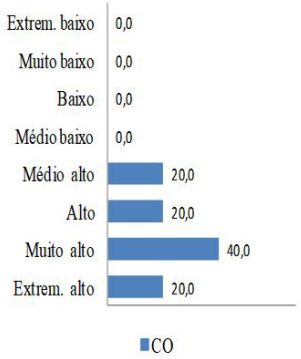

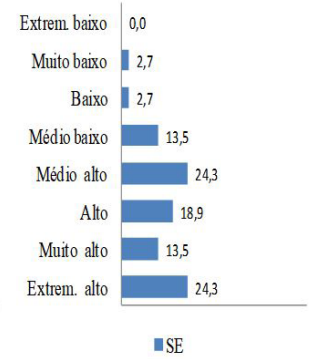

ISE

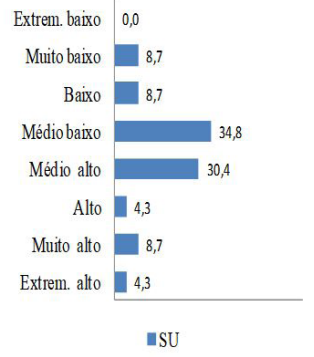

$\backsim \mathrm{SU}$ 
Figura 4. Distribuição das mesorregiões (\%) conforme classificação obtida para o fator 4 (intensidade de

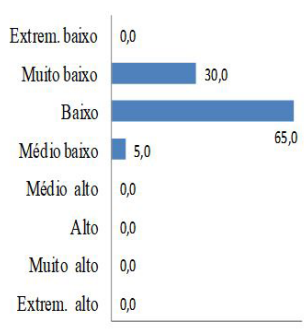

IINO

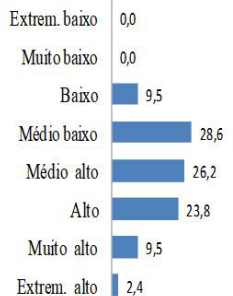

INE

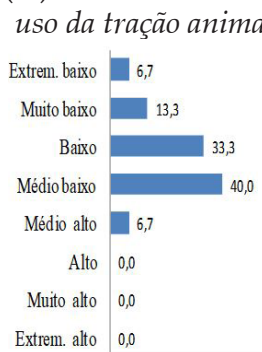

aCO

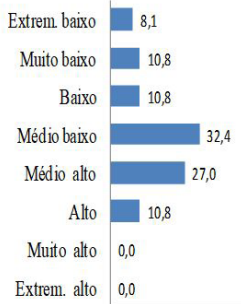

ISE

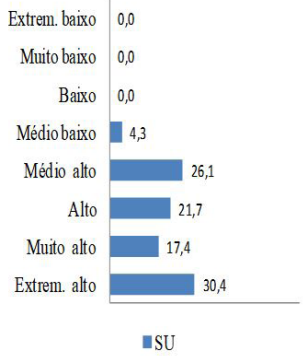

$\because S U$

Fonte: Resultados da pesquisa

possível inferir que, na região Sul, o uso da tração animal está em parte associado às condições de relevo (ou mesmo tamanho) que sejam impróprias ou inviabilizem o uso da mecanização. No Nordeste, ainda que essas mesmas condições possam estar atuando, o uso da tração animal deve estar associado a limitações de outra ordem (dotação de recursos, capital humano, assistência técnica etc.), que limitam a adoção de mecanização e de outras tecnologias. Ou seja, se no Sul o emprego da força animal figura como uma opção a mais, no Nordeste essa tem sido a única alternativa acessível para elevar a produtividade do trabalho numa agricultura que, de resto, tem baixos índices de uso das principais tecnologias ${ }^{7}$.

\subsection{Classificação geral das regiões a partir do índice de utilização de tecnologia}

Para se obter uma medida sintética das informações até aqui apresentadas, foi calculado um Índice de utilização de tecnologia para cada mesorregião. Os índices obtidos, reajustados por interpolação para uma escala de 0 a 100, encontram-se na Tabela 3. A classificação obtida pelas mesorregiões é representada na Figura 5. Nota-se que os índices mais elevados de uso das tecnologias consideradas concentram-se quase totalmente nas regiões Sul e Sudeste, com uma única exceção no Centro-Oeste. Na classificação adotada, esses índices atingem valores extremamente altos em regiões de São Paulo (metropolitana de São

\footnotetext{
Ainda que, por simplificação, a denominação desse fator tenha sido atrelada ao uso da tração animal, ele também se correlaciona com o percentual de estabelecimentos que utilizam financiamentos. Nesse sentido, a melhor classificação obtida pela agricultura familiar da região Nordeste quanto a esse fator é indício de que os financiamentos atingiram percentual expressivo de estabelecimentos agropecuários dessa região, pelo menos no ano em que foi realizado o censo. Tratam-se, porém, de financiamentos de menor valor, com poucos reflexos nos demais indicadores, possivelmente contribuindo para alguma elevação da intensidade de exploração da terra.
}

Paulo, Piracicaba, Araraquara, Ribeirão Preto, macro metropolitana paulista, Assis e Campinas), no Paraná (oeste), no Rio Grande do Sul (centro oriental, nordeste e noroeste), Santa Catarina (oeste, sul e Vale do Itajaí) e Distrito Federal.

Em seguida, com índices muito altos, encontram-se mesorregiões de São Paulo (Marília e São José do Rio Preto), Santa Catarina (norte e Grande Florianópolis), Paraná (sudoeste, sudeste, centro ocidental e norte central) e Rio de Janeiro (metropolitana). Com índices menores, porém considerados altos, estão regiões do Rio Grande do Sul (metropolitana de Porto Alegre e centro ocidental), de São Paulo (Araçatuba e Bauru), do Paraná (metropolitana de Curitiba, norte pioneiro, centro oriental e centro-sul), de Santa Catarina (serrana) e de Minas Gerais (sul/sudoeste de Minas e Triângulo Mineiro/ Alto Paranaíba).

Na região Centro-Oeste, exceto no Distrito Federal, predominam situações de índices médios, sobretudo médio baixos. No entanto, em três regiões de Goiás (noroeste, norte e leste) e uma de Mato Grosso do Sul (pantanais) foram encontrados índices baixos.

Já nas regiões Norte e Nordeste, na maior parte dos casos, prevalecem índices baixos ou muito baixos. Na região Norte, as únicas exceções são as mesorregiões Vale do Acre, norte do Amapá e oriental do Tocantins, com índices médio baixos. Na região Nordeste, com a mesma classificação, as exceções encontram-se no Ceará (norte, metropolitana de Fortaleza, centro-sul e sul), no Rio Grande do Norte (central e Agreste), Paraíba (Borborema), em Pernambuco (Agreste e metropolitana de Recife) e em Alagoas (Agreste e leste).

As localidades com os menores índices de utilização de tecnologia, classificados como muito baixos, estão situadas nessas duas regiões. A única exceção, situada no Sudeste, é a mesorregião norte de Minas Gerais. 
Tabela 3. Classificação das mesorregiões brasileiras segundo os Índices de utilização de tecnologias da agricultura familiar

\begin{tabular}{|c|c|c|c|c|c|c|c|}
\hline Mesorregião & IT & Índice & Classificação & Mesorregião & IT & Índice & Classificação \\
\hline Madeira-Guaporé - RO & $-0,414$ & 10,56 & Baixo & Vale do Rio Doce - MG & $-0,251$ & 16,39 & Médio baixo \\
\hline Leste Rondoniense - RO & $-0,548$ & 5,82 & Baixo & Oeste de Minas - MG & 0,085 & 28,37 & Médio alto \\
\hline Vale do Juruá - AC & $-0,570$ & 5,00 & Muito baixo & Sul/Sudoeste de Minas - MG & 0,393 & 39,36 & Alto \\
\hline Vale do Acre - AC & $-0,134$ & 20,57 & Médio baixo & Campo das Vertentes - MG & 0,021 & 26,09 & Médio alto \\
\hline Norte Amazonense - AM & $-0,530$ & 6,45 & Baixo & Zona da Mata - MG & $-0,249$ & 16,46 & Médio baixo \\
\hline Sudoeste Amazonense - AM & $-0,594$ & 4,15 & Muito baixo & Noroeste Espírito-santense - ES & 0,170 & 31,42 & Médio alto \\
\hline Centro Amazonense - AM & $-0,662$ & 1,72 & Muito baixo & Litoral Norte Espírito-santense-ES & 0,140 & 30,32 & Médio alto \\
\hline Sul Amazonense - AM & $-0,552$ & 5,66 & Baixo & Central Espírito-santense - ES & 0,090 & 28,55 & Médio alto \\
\hline Norte de Roraima - RR & $-0,676$ & 1,23 & Muito baixo & Sul Espírito-santense - ES & $-0,265$ & 15,88 & Médio baixo \\
\hline Sul de Roraima - RR & $-0,644$ & 2,37 & Muito baixo & Noroeste Fluminense - RJ & $-0,084$ & 22,34 & Médio baixo \\
\hline Baixo Amazonas - PA & $-0,454$ & 9,16 & Baixo & Norte Fluminense - RJ & 0,026 & 26,26 & Médio alto \\
\hline Marajó - PA & $-0,516$ & 6,94 & Baixo & Centro Fluminense - RJ & 0,039 & 26,72 & Médio alto \\
\hline Metropolitana de Belém - PA & $-0,376$ & 11,93 & Baixo & Baixadas - RJ & $-0,024$ & 24,50 & Médio baixo \\
\hline Nordeste Paraense - PA & $-0,478$ & 8,28 & Baixo & Sul Fluminense - RJ & $-0,080$ & 22,49 & Médio baixo \\
\hline Sudoeste Paraense - PA & $-0,418$ & 10,45 & Baixo & Metropolitana do Rio de Janeiro - RJ & 0,713 & 50,77 & Muito alto \\
\hline Sudeste Paraense - PA & $-0,537$ & 6,18 & Baixo & São José do Rio Preto - SP & 0,687 & 49,86 & Muito alto \\
\hline Norte do Amapá - AP & $-0,253$ & 16,32 & Médio baixo & Ribeirão Preto - SP & 1,264 & 70,43 & Extremam. alto \\
\hline Sul do Amapá - AP & $-0,711$ & 0,00 & Muito baixo & Araçatuba - SP & 0,535 & 44,42 & Alto \\
\hline Ocidental do Tocantins - TO & $-0,479$ & 8,25 & Baixo & Bauru - SP & 0,521 & 43,93 & Alto \\
\hline Oriental do Tocantins - TO & $-0,209$ & 17,88 & Médio baixo & Araraquara - SP & 1,540 & 80,26 & Extremam. alto \\
\hline Norte Maranhense - MA & $-0,612$ & 3,50 & Muito baixo & Piracicaba - SP & 1,550 & 80,63 & Extremam. alto \\
\hline Oeste Maranhense - MA & $-0,576$ & 4,79 & Muito baixo & Campinas - SP & 1,016 & 61,57 & Extremam. alto \\
\hline Centro Maranhense - MA & $-0,658$ & 1,88 & Muito baixo & Presidente Prudente - SP & 0,109 & 29,24 & Médio alto \\
\hline Leste Maranhense - MA & $-0,531$ & 6,40 & Baixo & Marília - SP & 0,736 & 51,60 & Muito alto \\
\hline Sul Maranhense - MA & $-0,312$ & 14,21 & Baixo & Assis - SP & 1,091 & 64,27 & Extremam. alto \\
\hline Norte Piauiense - PI & $-0,431$ & 9,98 & Baixo & Itapetininga - SP & 0,260 & 34,61 & Médio alto \\
\hline Centro-Norte Piauiense - PI & $-0,476$ & 8,36 & Baixo & Macro Metropolitana Paulista - SP & 1,108 & 64,87 & Extremam. alto \\
\hline Sudoeste Piauiense - PI & $-0,654$ & 2,03 & Muito baixo & Vale do Paraíba Paulista - SP & 0,043 & 26,88 & Médio alto \\
\hline Sudeste Piauiense - PI & $-0,625$ & 3,06 & Muito baixo & Litoral Sul Paulista - SP & 0,270 & 34,99 & Médio alto \\
\hline Noroeste Cearense - CE & $-0,310$ & 14,30 & Baixo & Metropolitana de São Paulo - SP & 2,093 & 100,00 & Extremam. alto \\
\hline Norte Cearense - CE & $-0,243$ & 16,68 & Médio baixo & Noroeste Paranaense - PR & $-0,007$ & 25,10 & Médio baixo \\
\hline Metropolitana de Fortaleza - CE & $-0,212$ & 17,79 & Médio baixo & Centro Ocidental Paranaense - PR & 0,633 & 47,93 & Muito alto \\
\hline Sertões Cearenses - CE & $-0,511$ & 7,12 & Baixo & Norte Central Paranaense - PR & 0,591 & 46,42 & Muito alto \\
\hline Jaguaribe - CE & $-0,389$ & 11,47 & Baixo & Norte Pioneiro Paranaense - PR & 0,384 & 39,04 & Alto \\
\hline Centro-Sul Cearense - CE & $-0,143$ & 20,24 & Médio baixo & Centro Oriental Paranaense - PR & 0,361 & 38,21 & Alto \\
\hline Sul Cearense - CE & $-0,242$ & 16,70 & Médio baixo & Oeste Paranaense - PR & 1,162 & 66,79 & Extremam. alto \\
\hline Oeste Potiguar - RN & $-0,376$ & 11,93 & Baixo & Sudoeste Paranaense - PR & 0,743 & 51,86 & Muito alto \\
\hline Central Potiguar - RN & $-0,027$ & 24,38 & Médio baixo & Centro-Sul Paranaense - PR & 0,291 & 35,73 & Alto \\
\hline Agreste Potiguar - RN & $-0,122$ & 21,00 & Médio baixo & Sudeste Paranaense - PR & 0,640 & 48,19 & Muito alto \\
\hline Leste Potiguar - RN & $-0,350$ & 12,85 & Baixo & Metropolitana de Curitiba - PR & 0,525 & 44,06 & Alto \\
\hline Sertão Paraibano - PB & $-0,413$ & 10,62 & Baixo & Oeste Catarinense - SC & 1,017 & 61,63 & Extremam. alto \\
\hline Borborema - PB & $-0,226$ & 17,29 & Médio baixo & Norte Catarinense - SC & 0,730 & 51,40 & Muito alto \\
\hline
\end{tabular}

Fonte: Resultados da pesquisa. 
Tabela 3. Continuação...

\begin{tabular}{|c|c|c|c|c|c|c|c|}
\hline Mesorregião & IT & Índice & Classificação & Mesorregião & IT & Índice & Classificação \\
\hline Agreste Paraibano - PB & $-0,383$ & 11,69 & Baixo & Serrana - SC & 0,424 & 40,48 & Alto \\
\hline Mata Paraibana - PB & $-0,512$ & 7,10 & Baixo & Vale do Itajaí - SC & 0,902 & 57,51 & Extremam. alto \\
\hline Sertão Pernambucano - PE & $-0,485$ & 8,04 & Baixo & Grande Florianópolis - SC & 0,636 & 48,04 & Muito alto \\
\hline São Francisco Pernambucano - PE & $-0,303$ & 14,53 & Baixo & Sul Catarinense - SC & 0,920 & 58,17 & Extremam. alto \\
\hline Agreste Pernambucano - PE & $-0,148$ & 20,08 & Médio baixo & Noroeste Rio-grandense - RS & 0,898 & 57,37 & Extremam. alto \\
\hline Mata Pernambucana - PE & $-0,436$ & 9,79 & Baixo & Nordeste Rio-grandense - RS & 0,951 & 59,28 & Extremam. alto \\
\hline Metropolitana de Recife - PE & $-0,196$ & 18,36 & Médio baixo & Centro Ocidental Rio-grandense-RS & 0,561 & 45,34 & Alto \\
\hline Sertão Alagoano - AL & $-0,362$ & 12,43 & Baixo & Centro Oriental Rio-grandense - RS & 0,999 & 60,97 & Extremam. alto \\
\hline Agreste Alagoano - AL & $-0,158$ & 19,70 & Médio baixo & Metropolitana de Porto Alegre - RS & 0,518 & 43,81 & Alto \\
\hline Leste Alagoano - AL & $-0,172$ & 19,20 & Médio baixo & Sudoeste Rio-grandense - RS & $-0,004$ & 25,18 & Médio baixo \\
\hline Sertão Sergipano - SE & $-0,412$ & 10,65 & Baixo & Sudeste Rio-grandense - RS & 0,080 & 28,20 & Médio alto \\
\hline Agreste Sergipano - SE & $-0,328$ & 13,65 & Baixo & Pantanais Sul Mato-grossense - MS & $-0,337$ & 13,31 & Baixo \\
\hline Leste Sergipano - SE & $-0,295$ & 14,81 & Baixo & $\begin{array}{l}\text { Centro Norte de Mato G. do } \\
\text { Sul - MS }\end{array}$ & 0,033 & 26,54 & Médio alto \\
\hline Extremo Oeste Baiano - BA & $-0,537$ & 6,20 & Baixo & Leste de Mato Grosso do Sul - MS & $-0,036$ & 24,07 & Médio baixo \\
\hline $\begin{array}{l}\text { Vale São-Franciscano da } \\
\text { Bahia - BA }\end{array}$ & $-0,504$ & 7,35 & Baixo & $\begin{array}{l}\text { Sudoeste de Mato Grosso do } \\
\text { Sul-MS }\end{array}$ & $-0,040$ & 23,91 & Médio baixo \\
\hline Centro Norte Baiano - BA & $-0,415$ & 10,53 & Baixo & Norte Mato-grossense - MT & $-0,019$ & 24,66 & Médio baixo \\
\hline Nordeste Baiano - BA & $-0,385$ & 11,60 & Baixo & Nordeste Mato-grossense - MT & $-0,109$ & 21,46 & Médio baixo \\
\hline Metropolitana de Salvador - BA & $-0,290$ & 15,01 & Baixo & Sudoeste Mato-grossense - MT & $-0,244$ & 16,63 & Médio baixo \\
\hline Centro Sul Baiano - BA & $-0,561$ & 5,35 & Baixo & Centro-Sul Mato-grossense - MT & $-0,269$ & 15,76 & Médio baixo \\
\hline Sul Baiano - BA & $-0,469$ & 8,62 & Baixo & Sudeste Mato-grossense - MT & 0,010 & 25,70 & Médio alto \\
\hline Noroeste de Minas - MG & $-0,071$ & 22,81 & Médio baixo & Noroeste Goiano - GO & $-0,298$ & 14,70 & Baixo \\
\hline Norte de Minas - MG & $-0,580$ & 4,65 & Muito baixo & Norte Goiano - GO & $-0,405$ & 10,91 & Baixo \\
\hline Jequitinhonha - MG & $-0,357$ & 12,61 & Baixo & Centro Goiano - GO & $-0,164$ & 19,49 & Médio baixo \\
\hline Vale do Mucuri - MG & $-0,306$ & 14,44 & Baixo & Leste Goiano - GO & $-0,302$ & 14,59 & Baixo \\
\hline Triâng. Min./ Alto Paranaíba-MG & 0,285 & 35,50 & Alto & Sul Goiano - GO & 0,046 & 26,99 & Médio alto \\
\hline Central Mineira - MG & $-0,064$ & 23,05 & Médio baixo & Distrito Federal - DF & 1,424 & 76,13 & Extremam. alto \\
\hline $\begin{array}{l}\text { Metropolit. de Belo Horizonte } \\
\text { - MG }\end{array}$ & $-0,153$ & 19,90 & Médio baixo & & & & \\
\hline
\end{tabular}

Fonte: Resultados da pesquisa.

Os demais casos situam-se no Acre (Vale do Juruá), no Amazonas (sudoeste e centro), em Roraima (sul e norte), no Amapá (sul), no Maranhão (norte, oeste e centro), no Piauí (sudeste e sudoeste).

\subsection{Entendendo as disparidades regionais: algumas hipóteses}

Dada a diversidade de situações da agricultura familiar no País, explicar as diferenças observadas é tarefa complexa. De início, é plausível assumir que esses resultados refletem mecanismos de escolha e adaptação dos agricultores familiares ao ambiente que enfrentam, marcado por limitações de recursos, dificuldades de acesso a políticas e ao mercado, com implicações negativas na adoção de tecnologia.

Parte dessas limitações encontra-se na dotação de recursos, em geral caracterizada por escassez de terra e recursos financeiros, e disponibilidade relativamente maior de trabalho. Além de limitar a adoção de tecnologia, essa realidade afeta sobretudo a produtividade da mão de obra, ao induzir a uma agricultura com baixos níveis de relação capital/trabalho.

Conforme a lógica do modelo de inovações induzidas (Hayami \& Ruttan, 1988), as mudanças tecnológicas respondem ao comportamento dos preços dos fatores que, por sua vez, refletem a dotação relativa dos mesmos. 
Figura 5. Índices de utilização de tecnologia na agricultura familiar das mesorregiões brasileiras, 2006

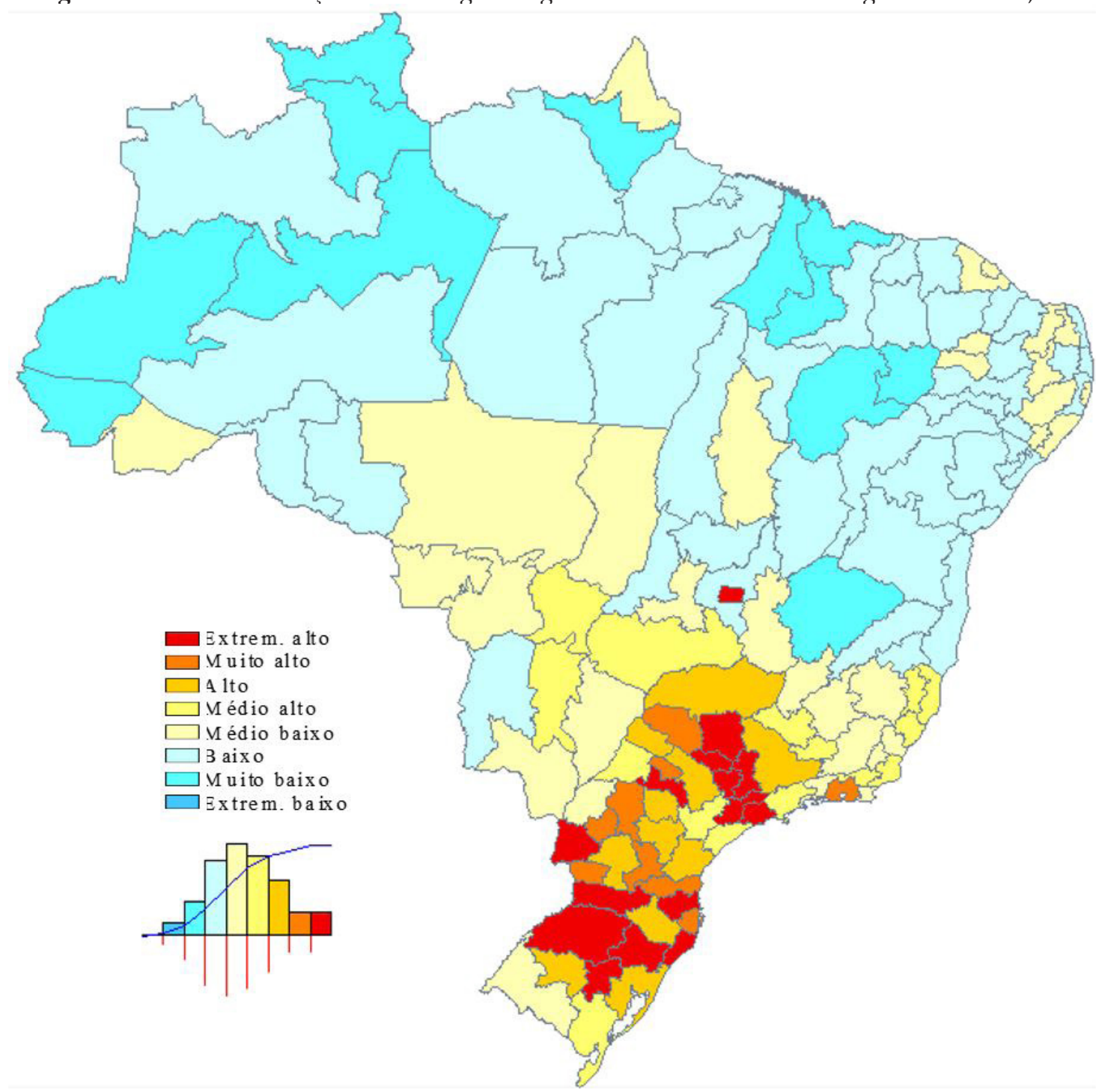

Fonte: Resultados da pesquisa.

Nessa lógica, em que fatores abundantes tendem a ser empregados mais intensivamente do que os fatores escassos, a agricultura familiar, com pouca terra e capital, com histórico de restrito acesso às políticas de crédito e mão de obra relativamente abundante, seguiu por uma via de uso mais intensivo do fator trabalho.

Em regiões onde as opções de ocupação restringem-se aos trabalhos no estabelecimento, deve ser baixo o custo de oportunidade da mão de obra dos membros da família. Isso ajuda a explicar os menores valores obtidos para a relação capital/trabalho para a maior parte das mesorregiões. As exceções, situadas em estados da região Sul e em São Paulo, podem estar associadas a situações de aumento do custo de oportunidade da mão de obra familiar. Nestes casos, a necessidade de adotar tecnologias para elevar a produtividade do trabalho fica mais evidente. De todo modo, a baixa relação capital/ trabalho observada nas demais regiões é um dado preocupante, pois revela uma agricultura com baixa produtividade do trabalho, indício de renda per capita também baixa ou insuficiente.

A escassez de terra reflete-se no tamanho reduzido dos estabelecimentos. Cerca de $40 \%$ dos estabelecimentos da agricultura familiar têm menos de 5 ha. A menor área média dos estabelecimentos familiares está na região Nordeste, seguida pelo Sul. No entanto, na primeira 
região há forte predominância de minifúndios, com cerca $59 \%$ dos estabelecimentos apresentando área inferior a 5ha. Na região Sul, o percentual de estabelecimentos com esse porte é de apenas $20 \%$. Além disso, na região Nordeste apenas 65\% dos agricultores familiares são proprietários, com cerca de $15 \%$ de arrendatários e parceiros, e 19\% de ocupantes. Nas demais regiões os proprietários correspondem a $80-90 \%$ do total e, com exceção da região Norte, é baixa proporção de ocupantes (Guanziroli et al., 2001). Como hipótese, agricultores na condição de não proprietários têm um horizonte de planejamento mais curto, enfrentam maiores dificuldades para acessar crédito e outras políticas, o que pode desestimular o investimento em tecnologia.

$O$ reduzido tamanho dos estabelecimentos pode restringir a adoção de algumas tecnologias, sobretudo as mecânicas, que em geral exigem maior escala de produção e acesso a recursos financeiros (Graziano da Silva, 1999). Em vários campos, segundo Souza Filho et al. (2011), é possível reduzir os efeitos da desvantagem associada à escala com a introdução de tecnologias mais adequadas. Não por acaso o uso da tração animal, ao contornar em parte essas limitações e contribuir para elevar a produtividade do trabalho, ainda permanece como alternativa tecnológica importante em regiões de agricultura familiar mais fragilizada, como as do Nordeste, ou mesmo em regiões de agricultura familiar mais moderna, com ocorre no Sul do País.

As limitações impostas pelo tamanho do estabelecimento realçam a importância da organização dos agricultores, mediante a qual é possível obter a escola mínima necessária para realizar investimentos e viabilizar certas tecnologias. Além disso, a organização aumenta o poder de negociação dos agricultores junto ao governo, facultando-lhes maior influência nos rumos de políticas públicas com efeitos na adoção de tecnologia (Souza Filho et al., 2011). Na ausência de organização, os agricultores têm maior dificuldade de organizar a produção e a comercialização, submetendo-se com frequência aos mecanismos de transferência de renda impostos por atravessadores, que limitam seus ganhos e reduzem as possibilidades de investimento em tecnologia (Buainain et al., 2002). Nesse aspecto também há contrastes regionais, conforme dados do Censo Agropecuário. Dessa fonte pode-se inferir que o percentual de agricultores associados a cooperativas, de quase $15 \%$ na região Sul, é de apenas $1 \%$ e $2 \%$ nas regiões Nordeste e Norte, respectivamente.
O emprego de tecnologia pela agricultura familiar é também afetado pela disponibilidade de recursos financeiros. A restrição de recursos financeiros é comum a parte dos estabelecimentos familiares, dada a precariedade das condições gerais em que produzem e se relacionam com os mercados. Sobretudo em regiões com menor custo de oportunidade da mão de obra, a escassez de recursos financeiros, próprios ou financiados, cria um viés contrário ao emprego de tecnologia capital-intensiva. Nessa ótica, considerando-se que no passado a distribuição do crédito rural, abundante e fortemente subsidiado, privilegiou os agricultores mais capitalizados, principalmente da região Centro-Sul do País (Graziano da Silva et al., 1983), há razões para que um quadro de disparidades tecnológicas se instale.

Mais recentemente, a escassez de recursos financeiros dos agricultores familiares vem sendo alvo de uma política específica, o Programa Nacional de Fortalecimento da Agricultura Familiar (Pronaf). No entanto, segundo algumas análises (Mattei, 2005; Silva et al., 2007), a lógica desse programa reproduz no seio da agricultura familiar os mecanismos de exclusão outrora operantes na política de crédito rural, e favorece agricultores mais capitalizados, sobretudo os da região Sul, em detrimento de agricultores mais pobres, principalmente os do Nordeste . $^{8}$ Além disso, mesmo após o advento desse programa permanece elevado o percentual de agricultores que não se utilizam de crédito (Souza et al., 2011) ${ }^{9}$. Por essas

\footnotetext{
8 Essa constatação incita uma discussão sobre a pertinência, ou não, da política de crédito como mecanismo de redução da desigualdade e inclusão de agricultores marginalizados. Essa discussão é aqui evitada, pois iria além dos objetivos do estudo. Sem entrar nos méritos das avaliações feitas, o fato é que, sendo ou não um mecanismo adequado para reduzir disparidades regionais ou entre tipos de agricultores, na prática a distribuição dos recursos vem sendo desigual. E, por essa razão, não se pode esperar dessa política redução das disparidades regionais entre agricultores familiares quanto ao uso de tecnologia, foco da presente pesquisa.

9 É preciso fazer a ressalva de que o baixo uso de financiamentos por pequenos estabelecimentos não pode ser diretamente associado à falta de crédito. Isso porque a capacidade de acessar o financiamento e a própria percepção de sua necessidade são afetadas por uma série de fatores, como nível educacional, acesso à assistência técnica, tipo de sistema produtivo, grau de organização etc. Segundo Souza et al. (2011), cerca de metade dos estabelecimentos familiares que informaram não ter utilizado financiamento em 2006 alegou não ter precisado. O medo da dívida, a burocracia e a existência de débito anterior representaram, juntos, a justificativa de $33,5 \%$ dos estabelecimentos. Esses motivos foram maiores na região Nordeste, onde o medo da dívida foi, isoladamente, apontado por quase $27 \%$ dos estabelecimentos como motivo para não utilizar financiamento.
} 
razões, a perspectiva de que tal programa contribua para reduzir as desigualdades no acesso a financiamentos e as disparidades tecnológicas e econômicas entre agricultores familiares torna-se menor.

De todo modo, constatou-se menor disparidade quanto à intensidade de exploração da terra. Diante do reduzido tamanho desses estabelecimentos, o uso mais intensivo desse fator mostra-se uma estratégia obrigatória. Disso resulta que a produtividade da terra mostra-se, em geral, mais elevada nos estabelecimentos familiares, ao contrário do que ocorre com a produtividade do trabalho (Guanziroli et al., 2012). Por outro lado, há evidências que indicam valores mais baixos de produtividade da terra nos estabelecimentos maiores, familiares ou não (Helfand et al., 2014). Também Alves et al. (2012) constataram que produtores malsucedidos economicamente possuem maior área e maior patrimônio por estabelecimento, e apresentam produtividade por hectare menor que os bem-sucedidos.

Nos estabelecimentos familiares, o tamanho da área condiciona o tipo de sistema de produção desenvolvido. Quanto maior a área, maior é a importância dos sistemas extensivos, com baixa exigência de mão de obra e menor produtividade da terra. Em áreas menores, predominam sistemas intensivos em mão de obra e voltados para o aumento da produtividade da terra, com destaque para horticultura e fruticultura (Guanziroli et al., 2001).

Isso foi evidenciado especialmente no caso das regiões metropolitanas onde, possivelmente, o alto preço da terra induz à intensificação do uso desse fator. Nessas localidades, o alto preço desse fator, mas também o maior custo de oportunidade da mão de obra (associado às opções alternativas de emprego ligadas direta ou indiretamente ao setor urbano) requerem uma agricultura com alta intensidade de exploração da terra ${ }^{10}$, baseada em atividades e tecnologias capazes de gerar maior renda por unidade de área. É possível considerar, ainda, o efeito da maior proximidade do mercado de produtos e insumos nessas regiões, condição mais favorável à adoção tecnológica (Souza Filho et al., 2011).

Por outro lado, os baixos valores para a intensidade de exploração da terra observados em regióes do Norte

10 Sob a hipótese de maior custo de oportunidade do trabalho nessas regiões, seriam também necessários investimentos em tecnologias poupadoras de mão de obra. No entanto, é plausível assumir que, pelo tamanho reduzido dos estabelecimentos, essa opção nem sempre se torna viável. e Centro-Oeste podem ser indício de menores restrições quanto ao tamanho ou ao preço desse fator nessas regiões. De fato,35e $43 \%$ dos estabelecimentos familiares das regiões Norte e Centro-Oeste, respectivamente, apresentam área superior a 50ha. Nas regiões Nordeste e Sul, estabelecimentos desse porte correspondem a apenas 8\% e 9\%, respectivamente (Guanziroli et al., 2001).

Não obstante, a dotação relativa dos fatores não explica isoladamente as disparidades observadas. Essa desigualdade pode estar também associada a outros fatores, cuja presença ou disponibilidade é maior em dada região do que em outras.

Um deles é a assistência técnica, cujo acesso é em geral limitado entre os agricultores familiares (Guanziroli et al., 2012). Mas há diferenças expressivas entre as regiões quanto a esse acesso, que é mais elevado entre agricultores familiares da região Sul, e mais restrito no Norte e Nordeste. Nestas duas regiões, cerca de 95\% ou mais dos estabelecimentos não utilizam assistência técnica, enquanto na região Sul quase a metade (47\%) dos estabelecimentos acessa esse serviço (Guanziroli \& Cardim, 2000). Os efeitos da desigualdade no acesso à assistência técnica tornam-se mais graves em face da provável disparidade entre essas regiões quanto ao capital humano de seus agricultores. São marcantes as diferenças entre essas regióes quanto à escolaridade, um importante componente do capital humano. Conforme Lemos (2012), os piores índices de escolaridade nas áreas rurais encontram-se nas regiões Nordeste e Norte, onde $27,7 \%$ e 16,7\% da população rural, respectivamente, era analfabeta em 2009. Nas áreas rurais da região Sul, no mesmo ano, essa taxa era de apenas $9,8 \%$.

A existência de canais de comercialização consolidados de processamento e comercialização, em que a produção se articula com cooperativas, agroindústrias etc., facilita a inserção do produto, reduzem a flutuação na renda e induzem à utilização de tecnologia (Souza Filho et al., 2011). Um importante exemplo a esse respeito são os sistemas integrados, comuns na agricultura da região Sul, onde mais de $15 \%$ dos estabelecimentos são integrados ao sistema agroindustrial. Essa prática, que é pouco representativa na região Nordeste, onde ocorre em cerca de apenas 0,5\% dos estabelecimentos, é importante para explicar o maior consumo intermediário da agricultura sulista (Conterato et al., 2014). Essa relação é complexa, com vantagens e desvantagens para os agricultores envolvidos. No entanto, contribui para 
elevar a utilização de novas tecnologias, com assistência técnica, fornecimento de insumos e redução dos riscos relativos à venda do produto.

Há que se considerar ainda as diferentes características regionais quanto à disponibilidade de infraestrutura, ao clima, ao solo etc. (Souza Filho et al., 2011). Nesse aspecto, Costa et al. (2005) observam que as áreas mais favoráveis à implantação de projetos de agricultura familiar situam-se nas regiões Sul, Sudeste e Centro-Oeste. Nessas regiões encontram-se melhores condições relativas à qualidade das terras, aspectos ambientais, infraestrutura e indicadores socioeconômicos, variáveis consideradas na análise dos autores. No quesito infraestrutura, um indicador das disparidades regionais é a disponibilidade de energia elétrica, essencial para adoção de determinados equipamentos. Nas regiões Norte e Nordeste, cerca de apenas $9 \%$ e 19\% dos estabelecimentos, respectivamente, têm acesso à energia elétrica. Esses valores são bem inferiores aos observados na região Sul (73\%), ou mesmo no Sudeste $(56 \%)$ e Centro-Oeste $(45 \%)$ (Guanziroli \& Cardim, 2000).

O padrão tecnológico é também condicionado pelos diferentes sistemas produtivos predominantes em cada região. Embora a diversificação produtiva seja uma característica comum ao segmento familiar, na existência de condições mais propícias, associadas a elementos históricos, culturais, de clima, solo, relevo, proximidade de centros urbanos, dentre outras, regiões e agricultores tendem a se especializar na produção de determinados produtos. As características dos sistemas de produção predominantes, se intensivos, semi-intensivos, extensivos, dentre outros, ajudam a entender o padrão tecnológico adotado pela região.

Esse fator deve ser importante na explicação da posição ocupada por determinadas regiões quanto às explorações animais, nas quais devem ter se especializado. $\mathrm{O}$ mesmo deve ser destacado em relação às regiões metropolitanas, onde a proximidade de grandes centros urbanos enseja o cultivo de hortifrutigranjeiros, sabidamente mais intensivos em mão de obra e tecnologias poupadoras de terra.

\section{Conclusões}

Com a pesquisa, buscou-se quantificar a intensidade de utilização das principais tecnologias pela agricultura familiar brasileira e obter uma visão geral das disparidades tecnológicas regionais. Como previsto, os resultados evidenciaram uma situação de grande heterogeneidade tecnológica na agricultura familiar.

De modo geral, constatou-se que a agricultura familiar com os maiores índices de utilização de tecnologia concentra-se, principalmente, nos estados da região Sul e Sudeste. Porém, nesta última a situação é bastante heterogênea, já que os melhores índices tendem a se restringir ao estado de São Paulo. Na região Centro-Oeste (exceto Distrito Federal), por sua vez, predominam situações de índices médios, enquanto nas regiões Norte e Nordeste, na maior parte dos casos, prevalecem índices baixos ou muito baixos.

Dada a abrangência do estudo e a diversidade de situações encontradas na agricultura familiar do País, explicar as causas das diferenças observadas é tarefa difícil, que vai além dos objetivos propostos. A hipótese aqui considerada é que a conformação do uso de tecnologia na agricultura familiar das diversas regióes resulta de uma adaptação dos agricultores a uma série de condicionantes, tais como: dotação relativa de terra, mão de obra e recursos financeiros; o acesso à política de crédito; infraestrutura regional; grau de interação com cooperativas, agroindústrias etc.; nível de capital humano; grau organização dos agricultores; acesso à assistência técnica; tipo de sistema de produção e atividades predominantemente desenvolvidas, dentre outras. No entanto, muitas outras causas podem estar envolvidas nesse processo. Dado o caráter exploratório da presente pesquisa, estudos mais aprofundados são necessários para testar as hipóteses elencadas, bem como investigar outros fatores condicionantes.

De todo modo, assumindo-se que a heterogeneidade tecnológica na agricultura familiar resulta de muitos fatores, políticas para reduzi-la não devem focar um único aspecto. Além disso, deve-se considerar que a agricultura familiar constitui-se de diferentes tipos de agricultores, em condições variadas de acesso à terra, tamanho dos estabelecimentos, desempenho econômico, acesso a políticas, inserção nos mercados etc. Trata-se, portanto, de uma diversidade de situações que o conceito de agricultura familiar, por demasiado abrangente, tende a ocultar. Na confecção de políticas para o desenvolvimento deste segmento, tais diferenças não devem ser esquecidas. 


\section{Referências}

Alves, E., \& Souza, G. S. (2015). Pequenos estabelecimentos também enriquecem? Pedras e tropeços. Revista de Política Agrícola, 24(3), 7-21.

Alves, E., Souza, G. S., \& Rocha, D. P. (2012). Lucratividade da agricultura. Revista de Política Agrícola, 21(2), 45-63.

Barros, G. S. C. (2010). Política agrícola no Brasil: subsídios e investimentos. In J. G. Gasques, J. E. R. Vieira Filho \& Z. Navarro (Orgs.), A agricultura brasileira: desempenho, desafios e perspectivas (pp. 237-258). Brasília: IPEA.

Buainain, A. M., Souza Filho, H. M., \& Silveira, J. M. (2002). Inovação tecnológica na agricultura e a agricultura familiar. In D. M. A. Lima \&J. Wilkinson. Inovação nas tradições da agricultura familiar (pp. 47-81). Brasília: Paralelo 15.

Cassales, F. L. G., Quirino, T. R., \& Sousa, C. P. (2002). Diagnóstico sociotécnico da agropecuária brasileira II: estabelecimentos (43 p.). Brasília: Embrapa Informação Tecnológica.

Conterato, M. A., Schneider, S., Fernandes, L. L., \& Libardoni, P. J. (2014). O consumo intermediário na agricultura: uma comparação entre agricultura familiar e não familiar no Brasil e nas regiões Sul e Nordeste. Revista Econômica do Nordeste, 45, 63-81.

Costa, T. C. C., Ramos, D. P., Pereira, N. R., Bueno, M. C. D., Baca, J. M., Fidalgo, E. C. C., Meirelles, M. S. P., Oliveira, R. P. O., \& Accioly, L. J. O. (2005). Suporte a decisão para qualidade de terras para a agricultura familiar. In Anais do $7^{\circ}$ Simpósio Brasileiro de Sensoriamento Remoto. São José dos Campos: INPE, p. 73-82.

Dias, G. L. S. (2010). A dificuldade de mudar: o caso da política agrícola no Brasil. In J. G. Gasques, J. E. R. Vieira Filho \& Z. Navarro (Org.), A agricultura brasileira: desempenho, desafios e perspectivas (pp. 259-274). Brasília: IPEA.

Espírito Santo, E. N. (1998). Agricultura no estado de Santa Catarina, período 1920-1985. Estudos Econômicos, São Paulo, 28(3), 453-473.

Figueiredo Filho, D. B., \& Silva Júnior, J. A. (2010). Visão além do alcance: uma introdução à análise fatorial. Opinião Pública, Campinas, 16(1), 160-185.

Fornazier, A., \& Vieira Filho, J. E. R. (2012). Heterogeneidade estrutural no setor agropecuário brasileiro: evidências a partir do censo agropecuário de 2006 (30 p.). Rio de Janeiro: IPEA.

Graziano da Silva, J. (1999). A modernização conservadora dos anos 70. In J. Graziano da Silva, Tecnologia e agricultura familiar (pp. 87-135). Porto Alegre: Universidade/UFRS.

Graziano da Silva, J., Kageyama, A. A., Romão, D. A., Wagner Neto, J. A., \& Pinto, L. C. G. (1983). Tecnologia e campesinato: o caso brasileiro. Revista de Economia Política, 3(4), 21-55.
Guanziroli, C. E., \& Cardim, S. E. C. S. (2000). Novo retrato da agricultura familiar: o Brasil redescoberto (76 p.). Brasília: INCRA/FAO/MDA.

Guanziroli, C. E., Buainain, A. M., \& Di Sabbato, A. (2012). Dez anos de evolução da agricultura familiar no Brasil: 1996 e 2006. Revista de Economia e Sociologia Rural, 50(2), 351-37.

Guanziroli, C. E., Romeiro, A., Buainain, A. M., Di Sabbato, A., \& Bittencourt, G. (2001). Agricultura familiar e reforma agrária no século XXI (288p.). Rio de janeiro: Garamond.

Hair Junior, J. F., Black, W. C., Babin, B. J., Anderson, R. E., \& Tatham, R. L. (2009). Análise multivariada de dados (6. ed., 688 p.). Porto Alegre, Bookman.

Harman, H. H. (1960). Modern factor analysis (474 p.). Chicago: University of Chicago Press.

Hayami, Y., \& Ruttan, V. W. (1988). Desenvolvimento agrícola: teoria e experiências internacionais (583 p.). Brasília: EMBRAPA-DPU.

Helfand, S. M., Moreira, A. R. B., \& Bresnyan Junior, E. W. (2014). Agricultura familiar, produtividade e pobreza no Brasil: evidências do censo agropecuário 2006. In S. Schneider, B. Ferreira, F. Alves (Orgs.), Aspectos multidimensionais da agricultura brasileira: diferentes visões do censo agropecuário 2006 (pp. 279-311). Brasília: Ipea.

Hoffmann, R. (1992). A dinâmica da modernização da agricultura em 157 microrregiões homogêneas do Brasil. Revista de Economia e Sociologia Rural, 30(4), 271-290.

Hoffmann, R., \& Kassouf, A. L. (1989). Modernização e desigualdade na agricultura brasileira. Revista Brasileira de Economia, 43, 273-303.

Instituto Brasileiro de Geografia e Estatísitca - IBGE. (2016). Sistema de recuperação automática de dados-SIDRA. Recuperado em 12 de agosto de 2016, de www.sidra.gov.br

Kageyama, A. A., \& Silva, J. F. G. (1983). Produtividade e emprego na agricultura brasileira. In L. G. Belluzzo \& R. Coutinho (Orgs.), Desenvolvimento capitalista no Brasil (pp. 192-222). São Paulo: Brasiliense.

Kim, J. O., \& Mueller, C. W. (1978). Introduction to factor analysis: what it is and how to do it (79 p.). Beverly Hills: Sage Publications.

Lattin, J., Carroll, J. D., \& Green, P. E. (2011). Análise de dados multivariados (475 p.). São Paulo: Cengage Learning.

Lemos, J. J. S. (2012). Mapa da exclusão social no Brasil: radiografia de um país assimetricamente pobre. (3. ed., 256 p.). Banco do Nordeste do Brasil: Fortaleza.

Madeira, S. A. (2012). Análise da modernização agrícola cearense no período de 1996 e 2006 (Dissertação de mestrado). Universidade Federal do Ceará, Centro de Ciências Agrárias, Departamento de Economia Agrícola, Mestrado em Economia Rural, Fortaleza. 92 p. 
Malhotra, N. K. (2006). Pesquisa de Marketing: uma orientação aplicada (4. ed., 720 p.). Porto Alegre: Bookman.

Manly, B. J. F. (2008). Métodos estatísticos multivariados: uma introdução (3. ed., 229 p.). Porto Alegre: Bookman.

Martine, G., \& Beskow, P. R. (1987). O modelo, os instrumentos e as transformações na estrutura de produção agrícola. In G. Martine \& R. C. Garcia (Orgs.), Os impactos sociais da modernização agrícola (pp. 19-39). São Paulo: Caetés.

Mattei, L. (2005). Impactos do Pronaf: análise de indicadores (136 p.). Brasília: Ministério do Desenvolvimento Agrário, Núcleo de Estudos Agrários e Desenvolvimento Rural.

Melo, C. O., \& Parré, J. L. (2007). Índice de desenvolvimento rural dos municípios paranaenses: determinantes e hierarquização. Revista de Economia e Sociologia Rural, 45(2), 329-365.

Mingoti, S. A. (2005). Análise de dados através de métodos de estatística multivariada: uma abordagem aplicada (297 p.). Belo Horizonte: Editora UFMG.

Monteiro, V. P., \& Pinheiro, J. C. V. (2004). Critério para implantação de tecnologias de suprimentos de água potável em municípios cearenses afetados pelo alto teor de sal. Revista de Economia e Sociologia Rural, 42(2), 365-387.

Pinto, A. (2000). Natureza e implicações da "heterogeneidade estrutural" da América Latina. In R. Bielschowsky (Org.), Cinqüenta anos de pensamento na CEPAL (vol. 2, pp. 567588). Rio de Janeiro/São Paulo: Record.

Queda, O. (1987). A extensão rural no Brasil: da anunciação ao milagre da modernização agrícola (201 p.). Piracibaca: USP.

Rebello, F. K., Santos, M. A. S., \& Homma, A. K. O. (2011). Modernização da agricultura nos municípios do Nordeste Paraense: determinantes e hierarquização no ano de 2006. Revista de Economia e Agronegócio, 9(2), 209-232.

Ribas, J. R., \& Vieira, P. R. C. (2011). Análise multivariada com o uso do SPSS (272 p.).Rio de Janeiro: Ciência Moderna.

Sayad, J. (1984). Crédito rural no Brasil: avaliação das críticas e das propostas de reforma (125 p.). São Paulo: FIPE/Pioneira.

Schneider, S., \& Cassol, A. (2014). Diversidade e heterogeneidade da agricultura familiar no Brasil e algumas implicações para políticas públicas. Cadernos de Ciência E Tecnologia, 31(2), 227-263.
Silva, F. F., Correa, V. P., \& Neder, H. D. (2007). Estudo comparativo da distribuição de recursos do PRONAF Crédito e Infra-estrutura, nas regiões Sul e Nordeste do Brasil: uma abordagem estatística. In A. C. Ortega \& N. Almeida Filho (Orgs.). Desenvolvimento Territorial, Segurança Alimentar e Economia Solidária (1. ed., vol. 1, p. 123-158). Campinas: Alínea.

Souza Filho, H. M., Buainain, A. M., Guanziroli, C. E., \& Batalha, M. O. (2004). Agricultura Familiar e Tecnologia no Brasil: características, desafios e obstáculos. In Anais do $42^{\circ}$ Congresso da Sociedade Brasileira de Economia, Sociologia e Administração Rural. Brasília: Sober.

Souza Filho, H. M., Buainain, A. M., Silveira, J. M. F. J., \& Vinholis, M. M. B. (2011). Condicionantes da adoção de inovações tecnológicas na agricultura. Cadernos de Ciência E Tecnologia, 28(1), 223-255.

Souza, P. M., Fornazier, A., Ponciano, N. J., \& Ney, M. G. (2011). Agricultura familiar versus agricultura não familiar: uma análise das diferenças nos financiamentos concedidos no período de 1999 a 2009. Revista Econômica do Nordeste, 42, 105-124.

Souza, P. M., \& Lima, J. E. (2003). Intensidade e dinâmica da modernização agrícola no Brasil e nas unidades da Federação. Revista Brasileira de Economia, 57(4), 795-824.

Stege, A. L., \& Parré, J. L. (2011). Desenvolvimento rural nas microrregiões do Brasil: um estudo multidimensional. Teoria e Evidência Econômica, 17(37), 160-193.

Szmrecsányi, T., \& Ramos, P. (2002). O papel das políticas governamentais na modernização da agricultura brasileira. In T. Szmrecsányi \& W. Suzigan (Orgs.). História econômica do Brasil contemporâneo (2. ed., pp. 227-250). São Paulo: HUCITEC/Associação Brasileira dos Pesquisadores em História Econômica/Editora da Universidade de São Paulo.

Tarsitano, M. A. A. (1992). A modernização e a desconcentração da terra da agricultura matogrossense: 1970/ 85. Revista de Economia Política, 12(4), 28-37.

Veiga, J. E. (1991). O desenvolvimento agrícola: uma visão histórica (240 p.). São Paulo: Editora da Universidade de São Paulo/HUCITEC. 
Apêndice A - Índices dos escores fatorias relativos ao uso de tecnologia pela agricultura familar das mesorregiões brasileiras

\begin{tabular}{|c|c|c|c|c|c|c|c|c|c|}
\hline Mesorregião & F1 & F2 & F3 & F4 & Mesorregião & F1 & F2 & F3 & F4 \\
\hline Madeira-Guaporé - RO & 18,02 & 5,38 & 38,85 & 16,45 & Vale do Rio Doce - MG & 9,92 & 11,54 & 47,67 & 32,59 \\
\hline Leste Rondoniense - RO & 8,33 & 4,64 & 45,55 & 24,99 & Oeste de Minas - MG & 19,10 & 8,75 & 71,43 & 35,12 \\
\hline Vale do Juruá - AC & 19,29 & 6,60 & 9,31 & 17,03 & Sul/Sudoeste de Minas - MG & 38,39 & 15,57 & 36,52 & 26,34 \\
\hline Vale do Acre - AC & 34,70 & 3,41 & 27,26 & 20,95 & Campo das Vertentes - MG & 10,64 & 13,18 & 69,78 & 38,53 \\
\hline Norte Amazonense - AM & 24,47 & 7,64 & 0,00 & 11,74 & Zona da Mata - MG & 5,77 & 14,10 & 45,16 & 39,16 \\
\hline Sudoeste Amazonense - AM & 19,20 & 8,00 & 3,67 & 14,63 & $\begin{array}{l}\text { Noroeste Espírito-santense } \\
\text { - ES }\end{array}$ & 20,70 & 20,51 & 40,37 & 29,83 \\
\hline Centro Amazonense - AM & 14,67 & 7,29 & 11,49 & 14,28 & $\begin{array}{l}\text { Litoral Norte Espírito- } \\
\text { santense - ES }\end{array}$ & 18,55 & 23,77 & 34,06 & 26,82 \\
\hline Sul Amazonense - AM & 18,84 & 6,71 & 13,33 & 16,42 & $\begin{array}{l}\text { Central Espírito-santense } \\
\text { - ES }\end{array}$ & 18,70 & 21,38 & 33,94 & 28,60 \\
\hline Norte de Roraima - RR & 15,30 & 5,04 & 18,36 & 11,74 & Sul Espírito-santense - ES & 9,37 & 15,82 & 33,77 & 30,73 \\
\hline Sul de Roraima - RR & 17,49 & 4,03 & 17,72 & 13,57 & Noroeste Fluminense - RJ & 8,35 & 13,30 & 67,60 & 33,21 \\
\hline Baixo Amazonas - PA & 23,88 & 6,23 & 11,72 & 17,25 & Norte Fluminense - RJ & 22,63 & 16,10 & 33,87 & 27,08 \\
\hline Marajó - PA & 24,14 & 7,99 & 4,78 & 8,42 & Centro Fluminense - RJ & 11,33 & 21,45 & 54,21 & 23,83 \\
\hline Metropolitana de Belém - PA & 19,78 & 13,79 & 8,64 & 15,85 & Baixadas - RJ & 2,04 & 20,65 & 72,20 & 29,41 \\
\hline Nordeste Paraense - PA & 21,48 & 8,22 & 7,06 & 18,89 & Sul Fluminense - RJ & 1,95 & 11,72 & 96,31 & 30,42 \\
\hline Sudoeste Paraense - PA & 25,17 & 4,68 & 19,89 & 15,41 & $\begin{array}{l}\text { Metropolitana do Rio de } \\
\text { Janeiro - RJ }\end{array}$ & 7,04 & 52,15 & 45,20 & 24,32 \\
\hline Sudeste Paraense - PA & 15,07 & 2,10 & 42,64 & 17,35 & São José do Rio Preto - SP & 57,66 & 10,83 & 47,16 & 11,80 \\
\hline Norte do Amapá - AP & 32,74 & 6,81 & 9,88 & 16,16 & Ribeirão Preto - SP & 83,70 & 17,25 & 26,75 & 4,74 \\
\hline Sul do Amapá - AP & 11,50 & 7,46 & 12,73 & 15,90 & Araçatuba - SP & 50,24 & 7,75 & 54,78 & 18,23 \\
\hline Ocidental do Tocantins - TO & 16,95 & 4,44 & 31,66 & 21,96 & Bauru - SP & 44,67 & 12,40 & 56,22 & 15,24 \\
\hline Oriental do Tocantins - TO & 30,95 & 5,25 & 26,52 & 16,52 & Araraquara - SP & 100,00 & 15,83 & 15,25 & 7,65 \\
\hline Norte Maranhense - MA & 11,57 & 9,03 & 10,03 & 26,11 & Piracicaba - SP & 84,25 & 19,87 & 47,93 & 10,43 \\
\hline Oeste Maranhense - MA & 17,09 & 6,32 & 13,95 & 19,47 & Campinas - SP & 50,00 & 28,42 & 44,10 & 18,56 \\
\hline Centro Maranhense - MA & 13,05 & 6,77 & 11,63 & 21,93 & Presidente Prudente - SP & 30,22 & 7,18 & 51,90 & 29,04 \\
\hline Leste Maranhense - MA & 18,63 & 8,26 & 5,21 & 22,52 & Marília - SP & 47,32 & 14,49 & 60,41 & 24,16 \\
\hline Sul Maranhense - MA & 29,12 & 5,41 & 14,60 & 19,98 & Assis - SP & 81,21 & 8,60 & 29,24 & 18,90 \\
\hline Norte Piauiense - PI & 18,67 & 9,54 & 7,22 & 29,37 & Itapetininga - SP & 34,33 & 13,70 & 41,23 & 23,14 \\
\hline Centro-Norte Piauiense - PI & 18,05 & 8,45 & 9,52 & 26,81 & $\begin{array}{l}\text { Macro Metropolitana } \\
\text { Paulista - SP }\end{array}$ & 41,92 & 39,24 & 36,94 & 24,01 \\
\hline Sudoeste Piauiense - PI & 13,37 & 5,66 & 5,78 & 31,74 & Vale do Paraíba Paulista - SP & 8,84 & 14,09 & 79,39 & 33,93 \\
\hline Sudeste Piauiense - PI & 12,78 & 5,90 & 4,15 & 38,40 & Litoral Sul Paulista - SP & 38,64 & 21,58 & 22,47 & 0,66 \\
\hline Noroeste Cearense - CE & 19,83 & 12,44 & 10,31 & 28,20 & $\begin{array}{l}\text { Metropolitana de São Paulo } \\
\text { - SP }\end{array}$ & 27,74 & 100,00 & 6,00 & 8,71 \\
\hline Norte Cearense - CE & 20,01 & 13,96 & 10,13 & 31,25 & Noroeste Paranaense - PR & 25,72 & 10,36 & 37,59 & 30,44 \\
\hline Metropolitana de Fortaleza-CE & 0,98 & 24,48 & 29,34 & 37,05 & $\begin{array}{l}\text { Centro Ocidental Paranaense } \\
\text { - PR }\end{array}$ & 63,76 & 6,59 & 12,17 & 37,09 \\
\hline Sertões Cearenses - CE & 13,52 & 8,44 & 12,05 & 33,93 & $\begin{array}{l}\text { Norte Central Paranaense } \\
\text { - PR }\end{array}$ & 53,82 & 13,13 & 20,39 & 30,00 \\
\hline Jaguaribe - CE & 10,68 & 10,35 & 19,05 & 45,41 & $\begin{array}{l}\text { Norte Pioneiro Paranaense } \\
\text { - PR }\end{array}$ & 44,95 & 10,86 & 20,23 & 38,69 \\
\hline Centro-Sul Cearense - CE & 25,88 & 12,83 & 1,82 & 39,04 & $\begin{array}{l}\text { Centro Oriental Paranaense } \\
\text { - PR }\end{array}$ & 36,43 & 12,27 & 38,42 & 38,62 \\
\hline Sul Cearense - CE & 23,58 & 11,59 & 0,99 & 38,28 & Oeste Paranaense - PR & 66,44 & 13,71 & 39,71 & 45,88 \\
\hline
\end{tabular}


Apêndice A - Continuação...

\begin{tabular}{|c|c|c|c|c|c|c|c|c|c|}
\hline Mesorregião & F1 & F2 & F3 & F4 & Mesorregião & F1 & F2 & F3 & F4 \\
\hline Oeste Potiguar - RN & 14,16 & 8,43 & 17,76 & 44,54 & Sudoeste Paranaense - PR & 43,48 & 10,17 & 45,95 & 68,75 \\
\hline Central Potiguar - RN & 24,63 & 9,40 & 25,57 & 47,27 & Centro-Sul Paranaense - PR & 37,82 & 9,48 & 28,14 & 45,75 \\
\hline Agreste Potiguar - RN & 21,63 & 10,80 & 14,79 & 49,75 & Sudeste Paranaense - PR & 55,52 & 11,20 & 4,18 & 55,51 \\
\hline Leste Potiguar - RN & 11,99 & 13,68 & 19,85 & 33,15 & $\begin{array}{l}\text { Metropolitana de Curitiba } \\
\text { - PR }\end{array}$ & 43,34 & 19,60 & 6,97 & 44,15 \\
\hline Sertão Paraibano - PB & 14,91 & 9,35 & 10,38 & 41,26 & Oeste Catarinense - SC & 43,59 & 9,12 & 67,29 & 87,89 \\
\hline Borborema - PB & 18,12 & 9,33 & 20,91 & 45,89 & Norte Catarinense - SC & 53,18 & 16,05 & 17,81 & 42,98 \\
\hline Agreste Paraibano - PB & 11,54 & 12,82 & 14,39 & 39,05 & Serrana - SC & 49,14 & 7,94 & 26,34 & 35,42 \\
\hline Mata Paraibana - PB & 1,58 & 19,25 & 9,74 & 33,92 & Vale do Itajaí - SC & 51,06 & 20,01 & 33,00 & 42,67 \\
\hline Sertão Pernambucano - PE & 12,09 & 9,32 & 8,77 & 42,18 & Grande Florianópolis - SC & 38,64 & 21,17 & 40,44 & 33,88 \\
\hline $\begin{array}{l}\text { São Francisco Pernambucano } \\
\text { - PE }\end{array}$ & 14,87 & 12,93 & 11,56 & 41,81 & Sul Catarinense - SC & 35,07 & 23,27 & 60,85 & 55,31 \\
\hline Agreste Pernambucano - PE & 18,32 & 14,44 & 14,57 & 43,36 & Noroeste Rio-grandense - RS & 62,62 & 3,68 & 24,93 & 74,89 \\
\hline Mata Pernambucana - PE & 6,25 & 19,77 & 7,00 & 30,20 & Nordeste Rio-grandense - RS & 59,65 & 15,41 & 36,60 & 35,49 \\
\hline Metropolitana de Recife - PE & 14,07 & 20,34 & 17,77 & 24,84 & $\begin{array}{l}\text { Centro Ocidental Rio- } \\
\text { grandense - RS }\end{array}$ & 50,77 & 7,04 & 29,14 & 49,47 \\
\hline Sertão Alagoano - AL & 18,05 & 7,39 & 2,44 & 53,86 & $\begin{array}{l}\text { Centro Oriental Rio- } \\
\text { grandense - RS }\end{array}$ & 41,10 & 16,33 & 34,79 & 100,00 \\
\hline Agreste Alagoano - AL & 20,68 & 15,38 & 4,75 & 41,04 & $\begin{array}{l}\text { Metropolitana de Porto } \\
\text { Alegre - RS }\end{array}$ & 31,56 & 20,73 & 31,01 & 51,77 \\
\hline Leste Alagoano - AL & 22,28 & 17,50 & 7,56 & 23,04 & Sudoeste Rio-grandense - RS & 24,51 & 4,93 & 56,41 & 35,48 \\
\hline Sertão Sergipano - SE & 18,07 & 7,22 & 14,22 & 35,31 & Sudeste Rio-grandense - RS & 27,18 & 7,66 & 22,74 & 63,30 \\
\hline Agreste Sergipano - SE & 14,71 & 12,32 & 16,53 & 36,09 & $\begin{array}{l}\text { Pantanais Sul Mato- } \\
\text { grossense - MS }\end{array}$ & 14,88 & 5,78 & 46,32 & 27,82 \\
\hline Leste Sergipano - SE & 16,93 & 14,76 & 14,14 & 26,74 & $\begin{array}{l}\text { Centro Norte de Mato G. } \\
\text { Sul - MS }\end{array}$ & 25,33 & 6,69 & 71,05 & 16,22 \\
\hline Extremo Oeste Baiano - BA & 11,81 & 8,56 & 17,63 & 29,59 & $\begin{array}{l}\text { Leste de Mato Grosso do } \\
\text { Sul - MS }\end{array}$ & 28,05 & 4,60 & 62,95 & 14,29 \\
\hline $\begin{array}{l}\text { Vale São-Franciscano da } \\
\text { Bahia - BA }\end{array}$ & 16,38 & 7,85 & 9,89 & 30,14 & $\begin{array}{l}\text { Sudoeste de Mato G. do } \\
\text { Sul - MS }\end{array}$ & 28,91 & 5,44 & 47,33 & 23,94 \\
\hline Centro Norte Baiano - BA & 20,10 & 7,87 & 11,02 & 29,23 & Norte Mato-grossense - MT & 36,20 & 2,53 & 47,23 & 14,52 \\
\hline Nordeste Baiano - BA & 22,03 & 7,64 & 8,76 & 30,38 & $\begin{array}{l}\text { Nordeste Mato-grossense } \\
\text { - MT }\end{array}$ & 36,16 & 0,00 & 58,59 & 0,00 \\
\hline Metropolitana de Salvador-BA & 13,45 & 15,93 & 16,83 & 31,46 & $\begin{array}{l}\text { Sudoeste Mato-grossense } \\
\text { - MT }\end{array}$ & 15,64 & 4,69 & 68,90 & 18,86 \\
\hline Centro Sul Baiano - BA & 11,45 & 8,06 & 11,80 & 35,47 & $\begin{array}{l}\text { Centro-Sul Mato-grossense } \\
\text { - MT }\end{array}$ & 21,12 & 6,80 & 38,02 & 22,07 \\
\hline Sul Baiano - BA & 16,45 & 8,13 & 18,96 & 24,26 & $\begin{array}{l}\text { Sudeste Mato-grossense - } \\
\text { MT }\end{array}$ & 29,00 & 4,73 & 62,37 & 17,60 \\
\hline Noroeste de Minas - MG & 22,41 & 4,63 & 59,46 & 31,02 & Noroeste Goiano - GO & 16,94 & 3,87 & 56,67 & 23,02 \\
\hline Norte de Minas - MG & 5,50 & 8,57 & 20,21 & 41,18 & Norte Goiano - GO & 17,50 & 4,33 & 38,54 & 23,72 \\
\hline Jequitinhonha - MG & 16,79 & 9,61 & 20,88 & 31,08 & Centro Goiano - GO & 13,02 & 8,15 & 64,62 & 29,72 \\
\hline Vale do Mucuri - MG & 12,81 & 9,73 & 38,55 & 32,09 & Leste Goiano - GO & 14,69 & 8,70 & 41,59 & 27,32 \\
\hline $\begin{array}{l}\text { Triâng. Mineiro/Alto Paranaíba } \\
\text { - MG }\end{array}$ & 30,86 & 5,02 & 87,20 & 22,55 & Sul Goiano - GO & 28,16 & 1,27 & 77,57 & 22,48 \\
\hline Central Mineira - MG & 7,66 & 5,77 & 100,00 & 32,82 & Distrito Federal - DF & 5,30 & 71,50 & 61,77 & 37,79 \\
\hline $\begin{array}{l}\text { Metropol. de Belo Horizonte } \\
\text { - MG }\end{array}$ & 0,00 & 16,09 & 67,35 & 40,36 & & & & & \\
\hline
\end{tabular}

